\title{
26. MAGNETIC PROPERTIES OF BLACK MUD TURBIDITES FROM ODP LEG 116, DISTAL BENGAL FAN, INDIAN OCEAN ${ }^{1}$
}

\author{
William W. Sager ${ }^{2}$ and Stuart A. Hall ${ }^{3}$
}

\begin{abstract}
Dark gray and black mud turbidites cored on ODP Leg 116 commonly yielded large magnetic susceptibility peaks. What is more, these peaks displayed different shapes suggesting variations in sedimentological processes. Consequently, a detailed study of the magnetic properties of two of these turbidites was undertaken to better understand the source of their unusual magnetism. Physical properties were measured as was the demagnetization behavior of sample natural remanent magnetizations (NRMs). Subsequently, an anhysteretic remanent magnetization (ARM) and saturation isothermal remanent magnetization (SIRM) were imparted to the samples, demagnetized, and various grain size tests based on the behavior of these remanences were applied. Finally, magnetic concentrates from two samples were examined with a scanning electron microscope with the capability to do energy dispersive X-ray (EDX) analysis. The turbidites stand out from surrounding layers because of their high susceptibilities, NRMs, ARMs, SIRMs, and ratios of ARM and SIRM to susceptibility. Their alternating field and thermal demagnetization properties and IRM acquisition curves are consistent with titanomagnetite grains as the primary magnetic mineral with some amount of hematite present. These properties are very similar to those published for samples from the Deccan flood basalts and suggest this formation as a possible source of the magnetic grains. Magnetic granulometry tests implied that the magnetic particles behave dominantly as single-domain and pseudo-single-domain grains. Moreover, they also implied that the large variation in susceptibility observed in the black mud turbidites results from a tenfold increase in the concentration of titanomagnetite grains. Electron microscope, EDX, and SIRM analyses revealed detrital titanomagnetites with typical sizes around 8-10 $\mu \mathrm{m}$, but as large as $20-25 \mu \mathrm{m}$. These are probably the dominant magnetic grains in the black mud turbidites; however, ARM and susceptibility frequency-dependence suggested that there may also be a submicrometer fraction present. Most of the observed titanomagnetite grains are tabular and some display exsolution lamellae, accounting for the pseudo-single-domain behavior despite their moderate sizes. We hypothesize that the magnetic mineral concentration variations are brought about by sedimentological factors. The heavier magnetic minerals may tend to sink to the bottom of a turbidite; however, sometimes turbidite turbulence may act to keep these tabular, medium-size grains in suspension longer than some other larger or more equidimensional grains. Consequently, the susceptibility peak shape may reflect the turbidite current velocities as well as other sedimentological factors.
\end{abstract}

\section{INTRODUCTION}

Ocean Drilling Program (ODP) Leg 116 cored at three closely-spaced sites $(717,718,719)$ on the distal fringe of the Bengal Fan, near the Equator in the Indian Ocean (Fig. 1). The sites were drilled where fan sediments are disrupted along with the underlying lithosphere by high-angle reverse faults caused by intraplate deformation (see Fig. 3 in Cochran, Stow, et al., 1989, p. 6). Sites 717 and 719 are companion sites located on the same fault block; the former was drilled as a reference site where the syn-deformation sediments are thickest and the latter was placed higher up on the block to sample an attenuated sediment section. Site 718 was drilled on the next fault block to the south primarily to examine heat flow and hydrothermal circulation.

A total of $2299.4 \mathrm{~m}$ of sediments was cored on Leg 116 of which $991.4 \mathrm{~m}$ was recovered. Most of the recovered sediments were turbidites, of which there are four main classes: (1) gray silt and silt-mud (Facies 1), (2) black or dark gray organic-rich mud (Facies 3), (3) light-gray organic-poor mud (Facies 2), and (4) olive-gray biogenic mud (Facies 4) (Cochran, Stow, et al., 1989). Magnetic susceptibility measurements were routinely made on

\footnotetext{
${ }^{1}$ Cochran, J. R., Stow, D.A.V., et al., 1990. Proc. ODP, Sci. Results, 116: College Station, TX (Ocean Drilling Program).

2 Departments of Oceanography and Geophysics, Texas A\&M University, College Station, TX 77843, U.S.A.

${ }^{3}$ Department of Geosciences, University of Houston, Houston, Texas 77004, U.S.A.
}

Leg 116 as a method of characterizing the recovered sediments. These measurements displayed unusual variations that appeared related to turbidites.

Magnetic susceptibility is defined by the relation $M=k H$, or alternatively $J=\chi H$, where $M$ is a magnetization per unit volume or $J$ is a magnetization per unit mass induced by the applied field $H$ in a material having volume susceptibility $k$ or mass susceptibility $\chi$ (Collinson, 1983). Thus the susceptibility of a sediment is a measure of the amount of magnetizable material it contains.

This magnetizable component includes not only the magnetic remanence-carrying ferromagnetic minerals, such as titanomagnetite, titanohematite, titanomaghemite, goethite, and pyrrhotite, but also paramagnetic minerals such as clays (e.g., nontronite, illite, chlorite, montmorillonite, etc.), ferrosilicates (e.g., biotite, pyroxenes, olivine, amphibole, etc.), iron carbonates (siderite) and iron sulfides (pyrite, chalcopyrite) (Collinson, 1983; Thompson and Oldfield, 1986). Furthermore, though many of the magnetic minerals found in sediments are lithogenic, some are authigenic minerals whose compositions depend on the depositional environment (Henshaw and Merrill, 1980; Karlin and Levi, 1985; Canfield and Berner, 1987). Because magnetite is common and usually has the highest susceptibility of these minerals, many authors have used susceptibility as a measure of the concentration of magnetite (Mooney and Bleifuss, 1953; Currie and Bornhold, 1983; Mullins, 1977; Thompson and Oldfield, 1986), though clearly the presence of other magnetic minerals can make the interpretation of this parameter more complex. 


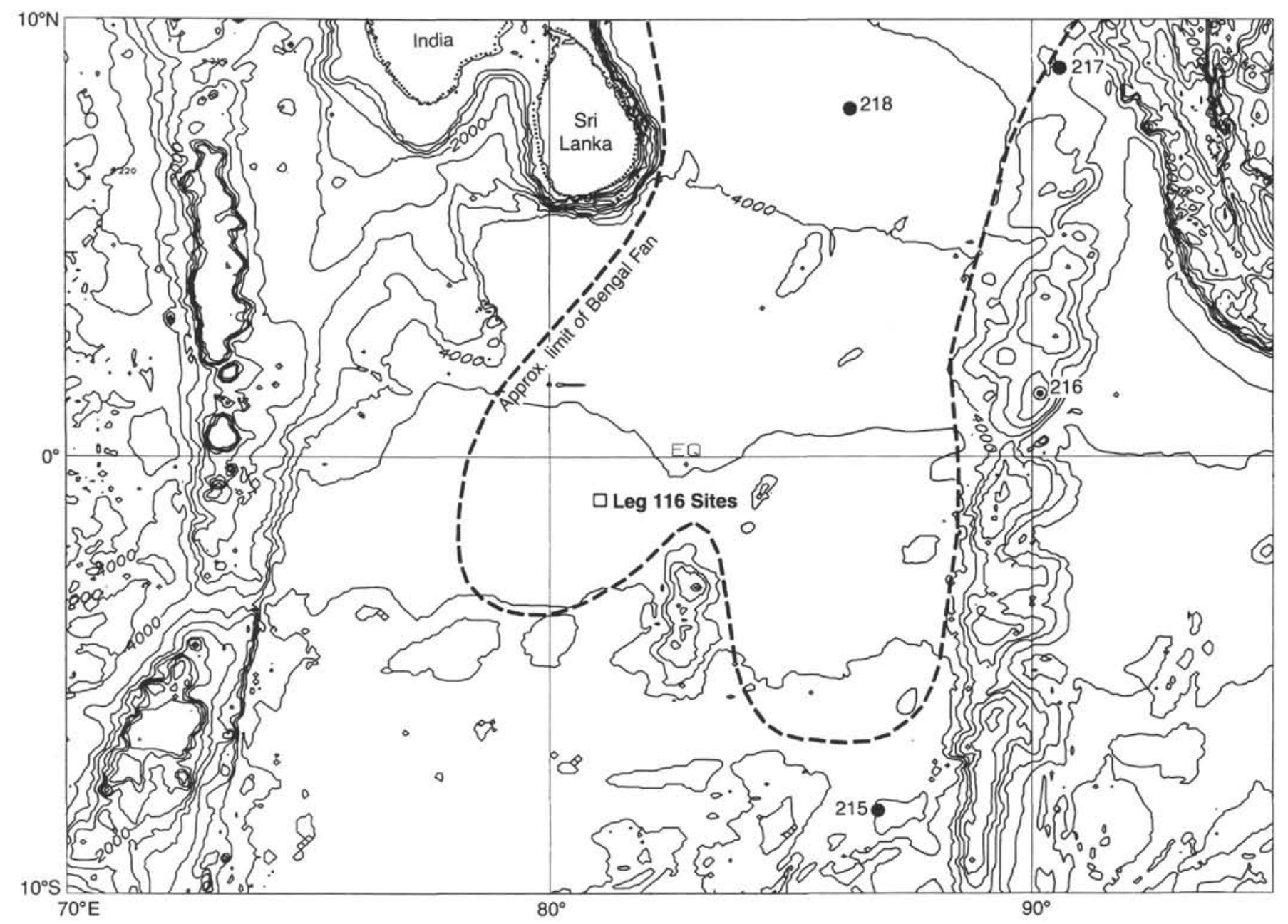

Figure 1. Bathymetric map showing location of ODP Leg 116 sites (square). Contours at 500-m intervals. Dashed line delineates approximate limit of Bengal fan. Solid circles show DSDP site locations. From Cochran, Stow, et al., 1989.

Leg 116 susceptibility measurements indicated that the recovered sediments are unusually magnetic. Not only is their magnetism strong, but it varies rapidly with depth by several orders of magnitude. Susceptibility values showed a background level of about $0.6 \times 10^{-5}$ to $2.5 \times 10^{-5} \mathrm{SI}$, punctuated by high-amplitude spikes with values as great as $118 \times 10^{-5} \mathrm{SI}$ (Cochran, Stow, et al., 1989). Moreover, these peaks were not uniformly distributed. Instead, they were concentrated at certain depths, different in each of the three holes drilled on Leg 116 (Fig. 2). Virtually all of the susceptibility peaks were found to correlate with turbidites. The highest values often occurred at turbidite bottoms and especially high values were recorded from Facies 3 black and dark-gray mud turbidites (Figs. 3-7). Additionally, the susceptibility signatures of Leg 116 turbidites displayed remarkable shape variations.

It was possible to group the turbidite susceptibility peaks into five categories by shape: (1) bell-shaped symmetric (Fig. 3), (2) ramp-shaped increasing downward (Figs. 4-5), (3) ramp-shaped increasing upward (Fig. 6), (4) double-peaked (Fig. 7), and (5) flat-topped and multipeaked (Fig. 7). Of the $89 \%$ of the peaks that could be classified at Site 717 , the first two categories were found to be predominant comprising $40 \%$ and $24 \%$, respectively, of the total. The next most common type was the flat-topped and multipeaked category (14\%) followed by the double-peaked $(7 \%)$ and ramp-shaped de- creasing downward (4\%) signatures (Cochran, Stow, et al., 1989).

These observations raise the question: what causes the observed magnetism of the turbidites and the shape variations of their susceptibility peaks? Other researchers on ODP cruises have also noted correlations between susceptibility and turbidites, but the signatures they found were sometimes different. Results similar to those from Leg 116 were found on Leg 112 where sandy turbidites from the Peru forearc were also noted for their high susceptibility values (Merrill, 1990). However, on Leg 115, calcareous turbidites from Hole 708A on the Somali Abyssal Plain near the Seychelles Bank were delineated by their low susceptibility values intruding on an otherwise high susceptibility record (Backman, Duncan, et al., 1988).

Another important question is whether the features observed in the susceptibility record can be used as a tool for stratigraphic correlation between holes. This technique has been used by some authors to correlate lithologic units in lake cores (Thompson et al., 1975; Bloemendal et al., 1979), but until recently it has not been widely pursued with deep-sea sediments (Robinson, 1986; Thompson and Oldfield, 1986). Between-hole correlations have been tried on a number of ODP cruises with mixed success. It has often been possible to correlate susceptibility signals between holes at the same site 

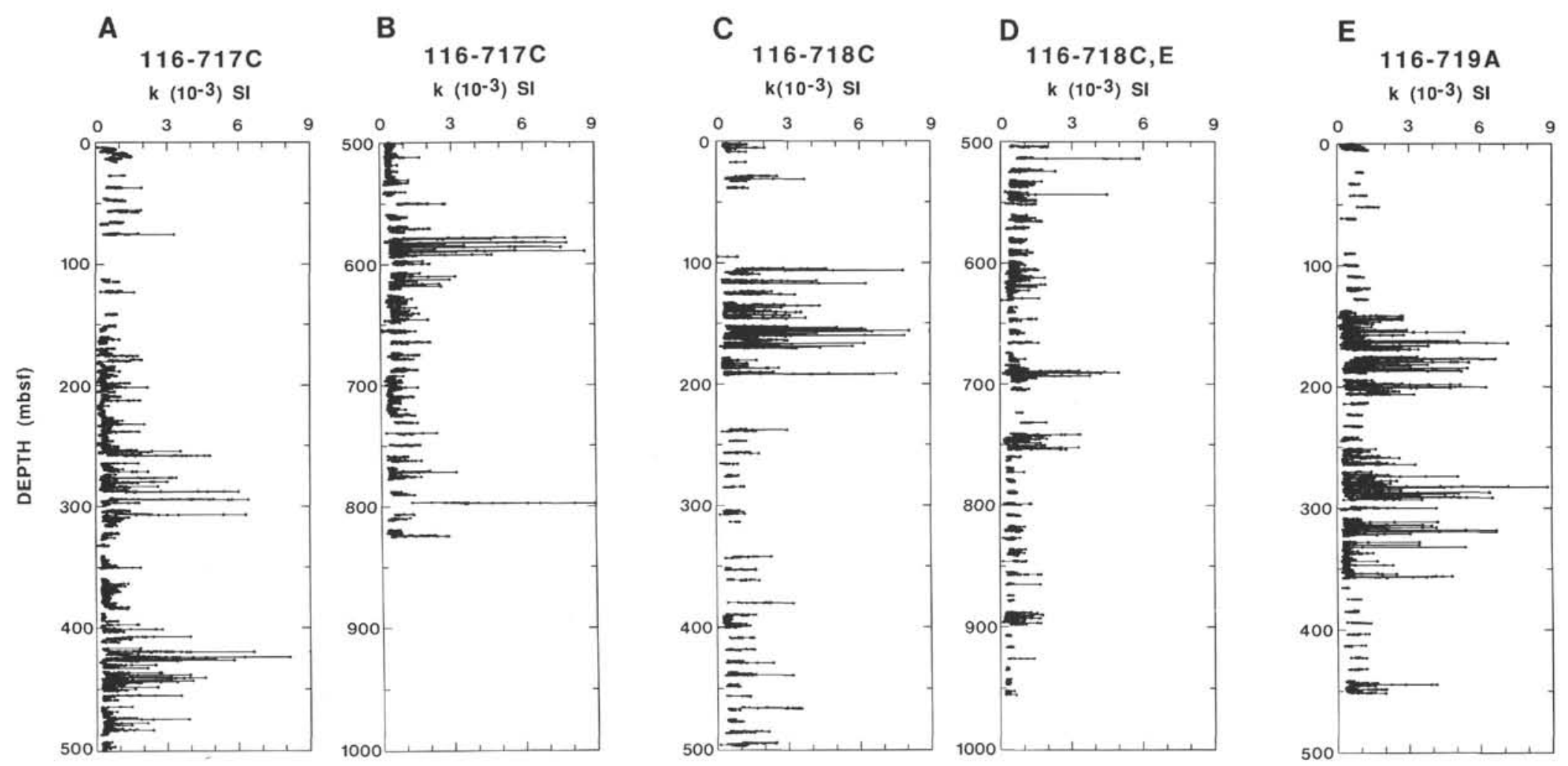

Figure 2. Shipboard susceptibility measurements plotted vs. depth for Leg 116 sites. A, B. Site 717. C, D. Site 718. E. Site 719. 
k $\left(10^{-3}\right) \mathrm{SI}$

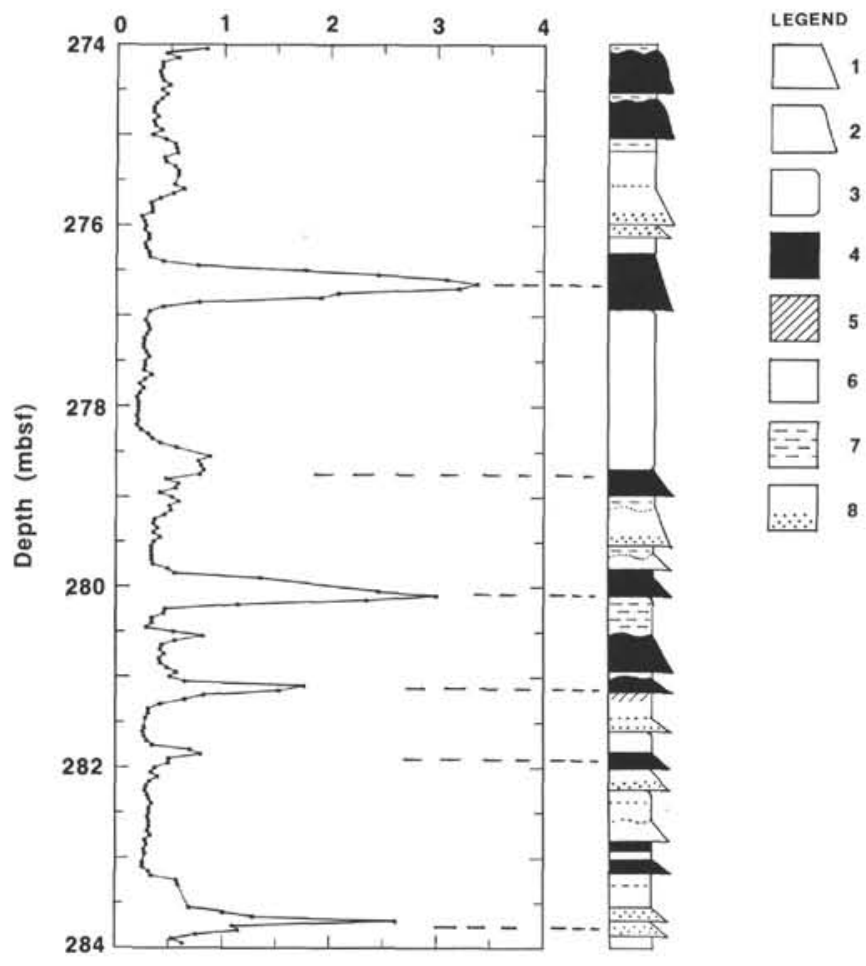

Figure 3. Shipboard volume magnetic susceptibility measurements (left) and lithostratigraphy (right) plotted vs. depth for Core 116-717C $33 \mathrm{X}$. These susceptibility peaks are typical of those that display a symmetric shape and are correlated with black mud turbidites. Dashed lines show correlation between turbidites and susceptibility peaks. The turbidite between 276 and 277 mbsf is one of the two examined in this report. Lithology legend is as follows: (1) turbidite, (2) indistinct turbidite, (3) structureless layer, (4) dark gray mud, (5) intermediate gray mud, (6) light gray mud, (7) pelagic clay, and (8) silt and mud.

(e.g., Leg 105, Srivastiva, Arthur, et al., 1987; Leg 108, Ruddiman, Sarnthein, et al., 1988; Leg 110, Mascle, Moore, et al., 1988; Leg 113, Barker, Kennett, et al., 1988; Leg 114, Ciesielski, Kristoffersen, et al., 1988; Leg 115, Backman, Duncan, et al., 1988), but only in one instance was it possible to infer convincing correlations for holes more than a few kilometers apart (Mascle, Moore, et al., 1988).

Our Leg 116 observations suggest that information about the depositional processes, particle sizes, environment, and compositions of turbidites are contained in their susceptibility signatures. Although Leg 116 cores contain hundreds of turbidites, we decided that the best way to address the magnetic properties of these layers was to investigate a small subset in detail. Thus we chose two representative Facies 3 turbidites, selected on the basis of their susceptibility signatures. Both are highly magnetic and each is typical of one of the two most common classes of susceptibility peaks. Both are late Miocene to early Pliocene dark-gray mud turbidites surrounded by lighter greenish gray muds. One, located in the upper part of Core 116-717C-33X (Fig. 3), displayed a symmetric susceptibility peak and the other, a similar turbidite from Core 116-717C-36X, yielded a ramped susceptibility signature (Fig. 4). We felt that the results of rock magnetic experiments on these turbidites would yield clues not only about the source of their magnetism, but also about the interesting shapes of the turbidite susceptibility signals. This information would be useful in interpreting the susceptibility record in the rest of the ODP Leg 116 cores.

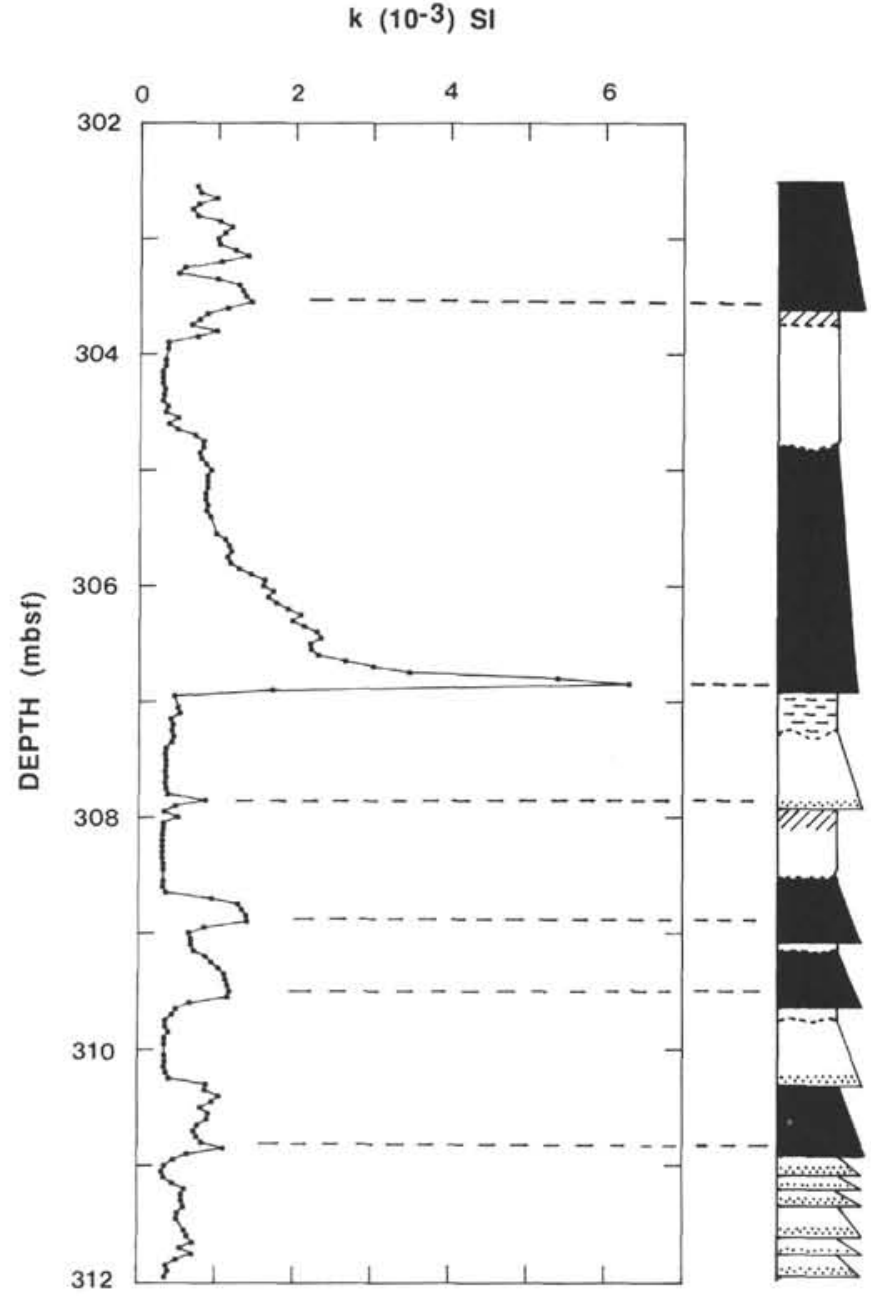

Figure 4. Shipboard volume magnetic susceptibility measurements (left) and lithostratigraphy (right) plotted vs. depth for Core 116-717C-36X. The turbidite between 304 and 307 mbsf is typical of the ramp-shaped, increasing-downward class and was one of the two examined in detail in this report. Lithostratigraphy symbols as in Figure 3.

\section{METHODS}

Volume susceptibility measurements were made aboard ship on whole-round core sections using a Bartington Instruments model MS-2 susceptibility meter with an 80 -mm sensing loop. This instrument uses an inducing field of $0.1 \mathrm{mT}$ RMS at a frequency of $470 \mathrm{~Hz}$ and is capable of measuring to $10^{-8} \mathrm{SI}$ in mass susceptibility and $10^{-5} \mathrm{SI}$ in volume susceptibility. All cores from Leg 116 were measured using a spacing of $5 \mathrm{~cm}$, yielding 17,870 readings (available from the ODP data bank). These are the data used to generate Figs. 2-7.

Samples were obtained from the two subject turbidites by pressing $6-\mathrm{cm}^{3}$ plastic boxes into the split face of the working half of the core. Eight were taken from $0.84 \mathrm{~m}$ of section from Core 116-717C-33X whereas 14 were removed from $2.58 \mathrm{~m}$ of Core 116-717C-36X (Table 1). In each case one or more samples were taken from sediments above and below the boundaries of the turbidites for comparison.

The susceptibility of each sample (Table 2) was measured with a Bartington MS-2 meter similar to the one on the JOIDES Resolution with the exception that the sensor used was a $36-\mathrm{mm}$ dual-frequency loop, designed for small discrete samples. The dual-frequency feature made it possible to measure the susceptibility in both high and low frequency 


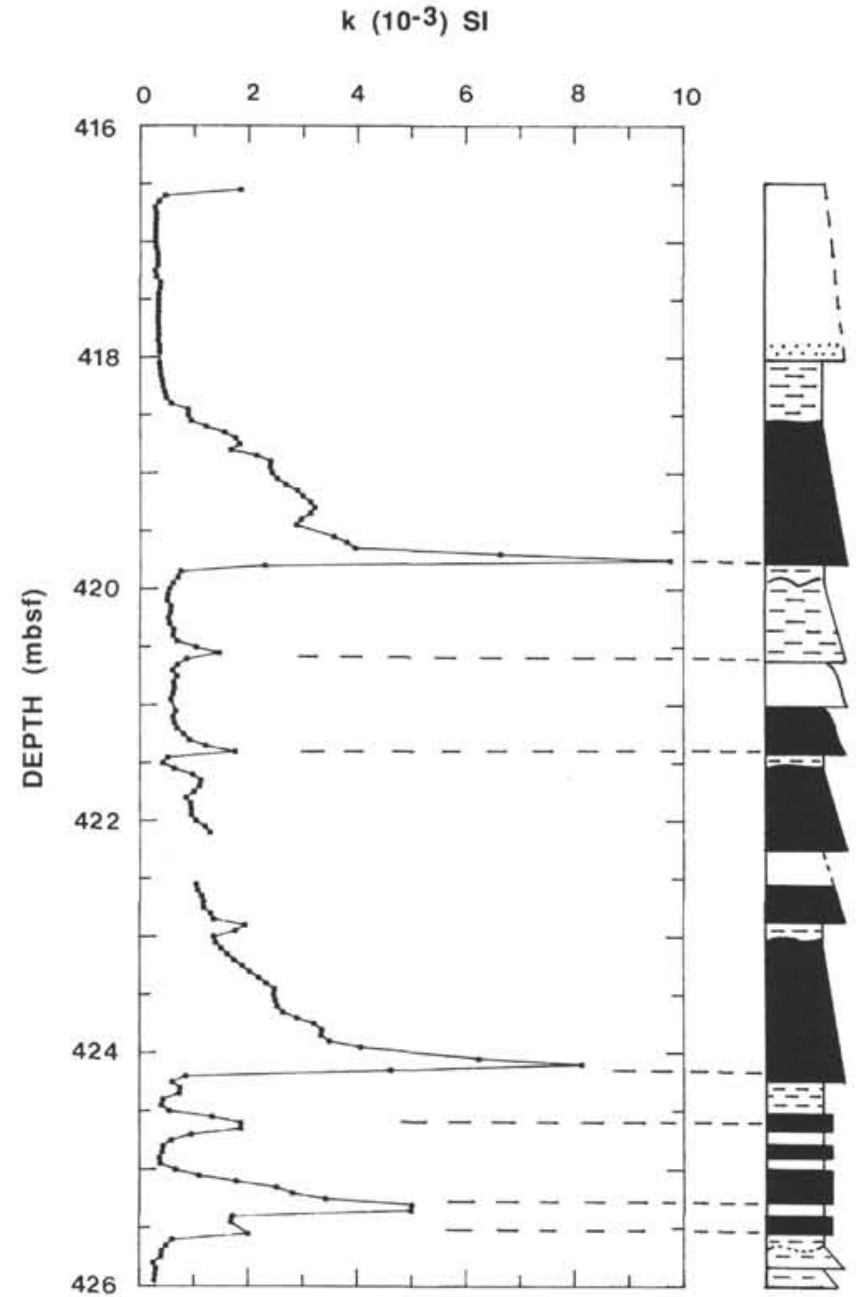

Figure 5. Shipboard volume magnetic susceptibility (left) and lithostratigraphy (right) and plotted vs. depth for Core 116-717C-48X. Conventions as in Figure 3.

$$
\text { k }\left(10^{-4}\right) \mathrm{SI}
$$

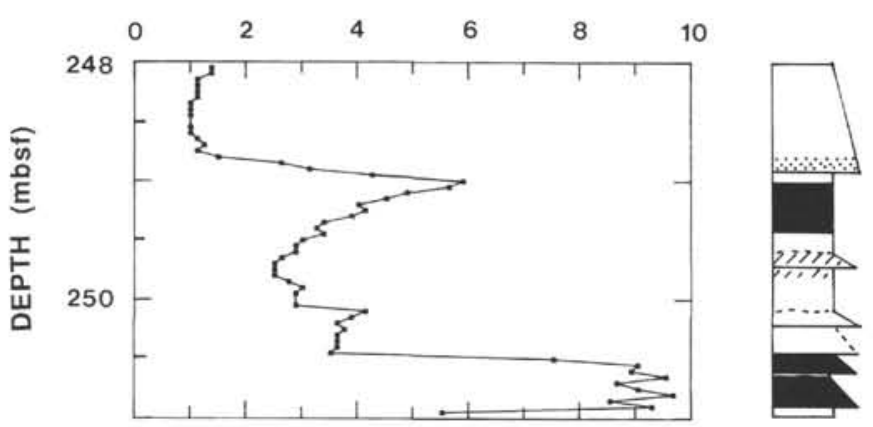

Figure 6. Shipboard volume magnetic susceptibility measurements (left) and lithostratigraphy (right) plotted vs. depth for a section of Core 116-717C-30X. This layer shows a susceptibility profile typical of the ramp-shaped, decreasing-downward class. Conventions as in Figure 3.

fields $(470 \mathrm{~Hz}$ and $4.7 \mathrm{kHz})$ and thus determine the frequency dependence of the susceptibility, $\chi_{f d}$, defined as $\chi_{f d}=$ $100 \times\left(\chi_{l f}-\chi_{h f}\right) / \chi_{l f}$ (where $h f$ and $l f$ denote high and low frequency), a parameter sensitive to magnetic grain size.

Magnetic remanence measurements (Tables 3-4) were made with a CTF cryogenic magnetometer. The natural remanent magnetization (NRM) of each sample was mea-
$116-717 \mathrm{C}-46 \mathrm{X}$

k $\left(10^{-4}\right) \mathrm{SI}$

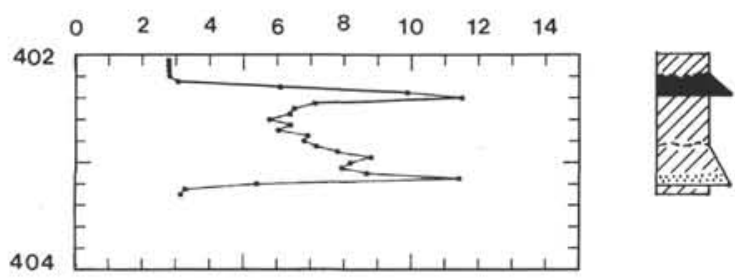

116-719A-30X

k $\left(10^{-3}\right) \mathrm{SI}$

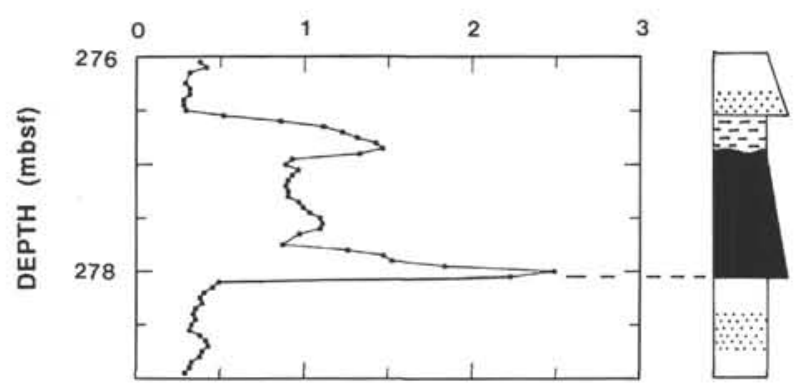

116-719A-33X

k $(10-3) \mathrm{SI}$

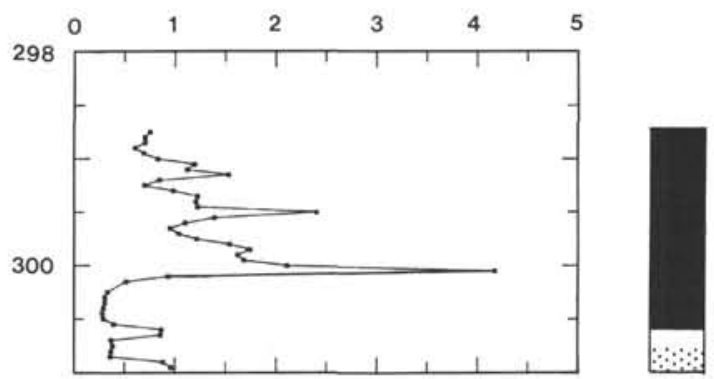

Figure 7. Shipboard volume magnetic susceptibility measurements and lithostratigraphy plotted vs. depth for turbidites in Cores 116-717C-46X, 116-719A-30X, and 116-719A-33X. The top and middle plots show susceptibility profiles typical of the doublepeaked category and the bottom plot shows a multipeaked turbidite that may represent several related turbidites. Conventions as in Figure 3 ,

sured and additional measurements were made during stepwise demagnetization using an alternating magnetic field (AF) with a strength between 2.5 and $200 \mathrm{mT}$. Two different artificial remanences were subsequently imparted to each sample, an anhysteretic remanent magnetization (ARM) and a saturation isothermal remanent magnetization (SIRM).

The ARM was imparted first by exposing each sample to a constant $0.05-\mathrm{mT}$ field and a slowly decaying $200-\mathrm{mT}$ alternating field. After measuring the ARM, additional measurements were made as each sample was stepwise demagnetized again, either past its mean destructive field (MDF) or to 200 $\mathrm{mT}$. The SIRM was imparted to each sample using an impulse magnetizer. This device uses capacitors to fire a brief surge of current through a coil which produces a field of up to $1200 \mathrm{mT}$ for about $2 \mathrm{~ms}$, enough time to create an IRM within the sample. Using this apparatus, five pilot samples were magnetized in progressively higher fields to observe differences in IRM acquisition of samples from within and outside the two 
Table 1. Sample stratigraphic parameters.

\begin{tabular}{|c|c|c|c|c|c|}
\hline $\begin{array}{c}\text { Section, } \\
\text { interval }(\mathrm{cm})\end{array}$ & $\begin{array}{l}\text { Depth } \\
\text { in core } \\
(\mathrm{cm})\end{array}$ & Color ${ }^{\mathrm{a}}$ & $\begin{array}{c}\text { Dry } \\
\text { weight } \\
\text { (g) }\end{array}$ & $\begin{array}{c}\text { Mean } \\
\text { particle size } \\
(\mu \mathrm{m})\end{array}$ & Position $^{b}$ \\
\hline \multicolumn{6}{|l|}{$116-717 C-33 X-$} \\
\hline $2,76-78$ & 226 & $5 Y 6 / 1$ & 7.15 & 8.5 & above \\
\hline $2,76-78$ & 246 & $5 \mathrm{Y} 4 / 1$ & 6.32 & 7.2 & in \\
\hline $2,108-110$ & 258 & $5 \mathrm{Y} 4 / 1$ & 6.68 & 8.0 & in \\
\hline $2,118-120$ & 268 & $5 Y 4 / 1$ & 7.10 & 7.4 & in \\
\hline $2,128-130$ & 278 & $5 \mathrm{Y} 4 / 1$ & 6.94 & 8.4 & in \\
\hline $2,137-139$ & 287 & $5 \mathrm{Y} 4 / 1$ & 4.88 & 6.8 & below \\
\hline $2,145-147$ & 295 & $5 Y 4 / 1$ & 5.28 & 6.6 & below \\
\hline $3,10-12$ & 310 & $5 Y 5 / 1$ & 5.77 & 6.5 & below \\
\hline \multicolumn{6}{|l|}{$116-717 C-36 X-$} \\
\hline $2,38-40$ & 188 & $5 Y 7 / 1$ & 6.84 & 7.4 & above \\
\hline $2,59-61$ & 209 & $5 Y 6 / 1$ & 7.74 & 7.4 & above? \\
\hline $2,72-74$ & 222 & $5 Y 5 / 1$ & 5.86 & 5.4 & in \\
\hline $2,104-106$ & 254 & $5 Y 5 / 1$ & 5.71 & 5.9 & in \\
\hline $2,124-126$ & 274 & $5 Y 4 / 1$ & 5.89 & 5.9 & in \\
\hline $2,144-146$ & 294 & $5 Y 4 / 1$ & 5.91 & 5.6 & in \\
\hline $3,19-21$ & 319 & $5 Y 5 / 1$ & 5.33 & 4.8 & in \\
\hline $3,43-45$ & 343 & $5 \mathrm{Y} 4 / 1$ & 6.65 & 5.0 & in \\
\hline $3,64-66$ & 364 & $5 \mathrm{Y} 4 / 1$ & 5.75 & 6.0 & in \\
\hline $3,80-82$ & 380 & $5 \mathrm{Y} 4 / 1$ & 6.05 & 6.7 & in \\
\hline $3,101-103$ & 401 & $5 \mathrm{Y} 4 / 1$ & 6.53 & 6.7 & in \\
\hline $3,113-115$ & 413 & $5 Y 5 / 1$ & 6.83 & 6.3 & in \\
\hline $3,128-130$ & 428 & $5 Y 5 / 1$ & 7.04 & 7.5 & in \\
\hline $3,146-148$ & 446 & $5 Y 6 / 1$ & 6.76 & 5.8 & below \\
\hline
\end{tabular}

a Color: color designation from Munsell soil color chart.

b Position: location relative to subject turbidite.

Table 2. Sample susceptibility.

\begin{tabular}{ccc}
\hline $\begin{array}{c}\text { Section, } \\
\text { interval }(\mathrm{cm})\end{array}$ & $\begin{array}{c}\text { Mass } \\
\text { susceptibility, } \\
\left(10^{-6} \mathrm{~m}^{3} \mathrm{~kg}-1\right)\end{array}$ & $\begin{array}{c}\text { Frequency } \\
\text { dependence, } \chi_{f d} \\
(\%)\end{array}$ \\
\hline $116-717 \mathrm{C}-33 \mathrm{X}-$ & & \\
$2,76-78$ & 0.12 & $0.2 \pm 1.5$ \\
$2,96-98$ & 0.44 & $1.9 \pm 0.4$ \\
$2,108-110$ & 1.32 & $1.6 \pm 0.1$ \\
$2,118-120$ & 1.55 & $1.8 \pm 0.1$ \\
$2,128-130$ & 1.01 & $4.3 \pm 0.2$ \\
$2,137-139$ & 0.17 & $0.0 \pm 1.5$ \\
$2,145-147$ & 0.13 & $2.7 \pm 1.8$ \\
$3,10-12$ & 0.12 & $1.1 \pm 1.8$ \\
$116-717 \mathrm{C}-36 \mathrm{X}-$ & & \\
$2,38-40$ & 0.13 & $-0.1 \pm 1.3$ \\
$2,59-61$ & 0.16 & $-0.3 \pm 1.0$ \\
$2,72-74$ & 0.36 & $0.4 \pm 0.6$ \\
$2,104-106$ & 0.54 & $1.2 \pm 0.4$ \\
$2,124-126$ & 0.48 & $1.1 \pm 0.4$ \\
$2,144-146$ & 0.51 & $0.8 \pm 0.4$ \\
$3,19-21$ & 0.68 & $1.4 \pm 0.3$ \\
$3,43-45$ & 0.87 & $1.3 \pm 0.2$ \\
$3,64-66$ & 0.81 & $0.7 \pm 0.3$ \\
$3,80-82$ & 1.00 & $0.7 \pm 0.2$ \\
$3,101-103$ & 1.04 & $1.3 \pm 0.2$ \\
$3,113-115$ & 1.21 & $0.8 \pm 0.1$ \\
$3,128-130$ & 1.72 & $0.7 \pm 0.1$ \\
$3,146-148$ & 0.17 & $0.0 \pm 1.0$ \\
\hline
\end{tabular}

turbidites. The remaining samples were simply saturated in one step. All samples were again stepwise demagnetized and measured in alternating fields up to the MDF of the sample or $200 \mathrm{mT}$. Lastly, two samples were saturated again and subjected to a detailed stepwise thermal demagnetization study, from $100^{\circ}-575^{\circ} \mathrm{C}$, to garner additional information about the blocking temperatures of the remanence-carrying minerals in the turbidites.

Following the magnetic experiments, measurements of physical parameters were made. Sample colors were quantified using the Munsell soil color charts (the colors of the two samples treated to thermal demagnetization were measured before heating). Because there was a significant difference in the darkness of the sediments across the turbidite boundaries, a simple gray scale was constructed and compared to the core at intervals of $10 \mathrm{~cm}$. The weight of each sample was measured after it was dried for 3 days at $100^{\circ} \mathrm{C}$. Additionally, a small portion of each sample was disaggregated in a solution of sodium hexametaphosphate and distilled water so that grain sizes could be determined with a LABTEC-100 laser particle analyzer. Although some sedimentologists question the absolute accuracy of this instrument, it does provide a quick and relatively precise measure of relative grain size variations.

Finally, a portion of two samples, from the most magnetic part of the two study turbidites, were examined with a JEOL JSM-35CF scanning electron microscope (SEM) equipped with a Tracor-Northern model 2000 energy dispersive X-ray (EDX) spectrometer used to identify magnetic grains. Magnetic concentrates were made simply by suspending the sediment in a solution of sodium hexametaphosphate and distilled water, immersing in this solution a strong permanent magnet wrapped in filter paper, and removing the filter paper and the concentrate stuck to it after an hour. The concentrates were examined with the SEM as was a bit of each sample not treated to separation.

\section{RESULTS}

\section{Physical Properties}

The study turbidites clearly stand out from the sediments surrounding them in terms of color and darkness; however, the particle sizes and weights of samples do not vary greatly across the turbidite boundaries. The Core 116-717C-33X turbidite is uniformly dark, whereas the Core $116-717 \mathrm{C}-36 \mathrm{X}$ turbidite has a band of lighter material in the middle (Fig. 8). Nevertheless, it was recognized as a single turbidite unit by the shipboard sedimentologists (Fig. 4). The mean grain size of samples directly above both turbidites is greater than samples within each turbidite (Fig. 9), probably because the layer above is the base of another turbidite. There is a slight trend toward increasing particle size with depth in the Core 116-717C-36X turbidite; although, Samples 116-717C-36X-3, $19-21 \mathrm{~cm}$, and $116-717 \mathrm{C}-36 \mathrm{X}-3,43-45 \mathrm{~cm}$, appear to reverse the trend (Fig. 9). The lighter color of this part of the turbidite plus the decrease in particle sizes suggests that this turbidite may in fact consist of two separate layers; however, this trend is not observed in the magnetic parameters as will be shown below. A comparison of the range of grain sizes of samples from inside and outside the turbidites indicates that those inside have a distribution shifted slightly toward larger particles (Fig. 9). In these samples there is a small fraction of grains in the $31-44-\mu \mathrm{m}$ range that is absent in samples from outside.

A similar pattern holds for the sample weights. Samples from above the study turbidites are heavier than those within the turbidites (Fig. 10) and there is a slight trend of increasing weight downcore within both turbidites. The heaviest samples are from the turbidite bottoms, suggesting that the heavier 
Table 3. Sample remanence data.

\begin{tabular}{cccccrr}
\hline $\begin{array}{c}\text { Section, } \\
\text { interval }(\mathrm{cm})\end{array}$ & $\begin{array}{c}\mathrm{NRM}^{\mathrm{a}} \\
\left(10^{-5} \mathrm{Am}^{2} \mathrm{~kg}^{-1}\right)\end{array}$ & $\begin{array}{c}\mathrm{MDF}^{\mathrm{b}} \\
(\mathrm{mT})\end{array}$ & $\begin{array}{c}\mathrm{ARM}^{\mathrm{c}} \\
\left(10^{-5} \mathrm{Am}^{2} \mathrm{~kg}^{-1}\right)\end{array}$ & $\begin{array}{c}\mathrm{MDF} \\
(\mathrm{mT})\end{array}$ & $\begin{array}{r}\mathrm{SIRM}^{\mathrm{d}} \\
\left(10^{-5} \mathrm{Am}^{2} \mathrm{~kg}^{-1}\right)\end{array}$ & $\begin{array}{r}\mathrm{MDF} \\
(\mathrm{mT})\end{array}$ \\
\hline $116-717 \mathrm{C}-33 \mathrm{X}-$ & & & & & & \\
$2,76-78$ & 0.190 & 133.0 & 0.47 & 37.3 & 42.14 & 110.0 \\
$2,96-98$ & 1.483 & 7.7 & 4.51 & 23.6 & 463.37 & 49.0 \\
$2,108-110$ & 6.353 & 6.5 & 21.58 & 27.1 & 1421.33 & 17.7 \\
$2,118-120$ & 10.558 & 7.2 & 29.34 & 27.2 & 1733.96 & 27.2 \\
$2,128-130$ & 4.999 & 6.7 & 22.26 & 26.5 & 1015.69 & 23.0 \\
$2,137-139$ & 0.050 & 4.5 & 0.57 & 52.9 & 33.14 & 129.2 \\
$2,145-147$ & 0.027 & 2.4 & 0.42 & 50.0 & 25.39 & 102.0 \\
$3,10-12$ & 0.029 & 37.8 & 0.33 & 44.4 & 21.23 & 121.8 \\
$116-717-36 \mathrm{X}-$ & & & & & & 12.8 \\
$2,38-40$ & & & & & & 121.4 \\
$2,59-61$ & 0.046 & 60.0 & 0.41 & 51.3 & 26.30 & 39.0 \\
$2,72-74$ & 0.026 & $?$ & 0.63 & 55.7 & 322.44 & 22.9 \\
$2,104-106$ & 1.908 & 8.5 & 15.73 & 29.5 & 543.83 & 20.7 \\
$2,124-126$ & 0.747 & 41.8 & 18.94 & 32.0 & 421.90 & 21.5 \\
$2,144-146$ & 0.591 & 19.2 & 11.76 & 32.0 & 487.12 & 21.4 \\
$3,19-21$ & 1.132 & 6.3 & 14.99 & 30.0 & 793.18 & 21.3 \\
$3,43-45$ & 1.520 & 5.0 & 39.89 & 30.7 & 965.95 & 18.3 \\
$3,64-66$ & 16.944 & 8.0 & 26.04 & 26.4 & 906.62 & 18.2 \\
$3,80-82$ & 3.528 & 25.3 & 21.50 & 38.3 & 1126.65 & 17.3 \\
$3,101-103$ & 2.541 & 12.0 & 24.40 & 28.3 & 1182.00 & 17.4 \\
$3,113-115$ & 20.342 & 8.9 & 25.44 & 29.4 & 1459.80 & 17.0 \\
$3,128-130$ & 4.909 & 13.5 & 25.57 & 30.0 & 2343.45 & 16.4 \\
$3,146-148$ & 7.068 & 8.8 & 34.53 & 29.5 & 39.94 & 145.7 \\
\hline
\end{tabular}

a NRM: natural remanent magnetization.

b MDF: mean destructive field.

c ARM: anhysteretic remanent magnetization.

d SIRM: saturation isothermal remanent magnetization.

Table 4. Artificial remanence test data.

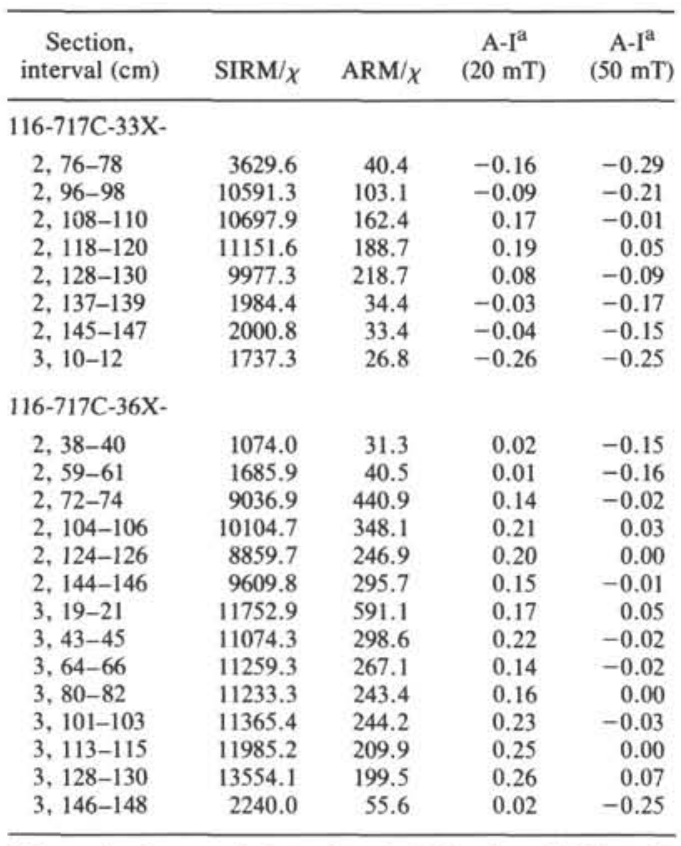

${ }^{a}$ Normalized magnetic intensity of ARM minus SIRM at 20 $\mathrm{mT}$ and $50 \mathrm{mT}$ demagnetization steps.

minerals or greater concentrations of heavy minerals preferentially settled to the base of the layer.

\section{Susceptibility}

Mass susceptibility values obtained from the discrete samples yielded trends virtually identical to those found in the reconnaissance whole-core volume-susceptibility mea-
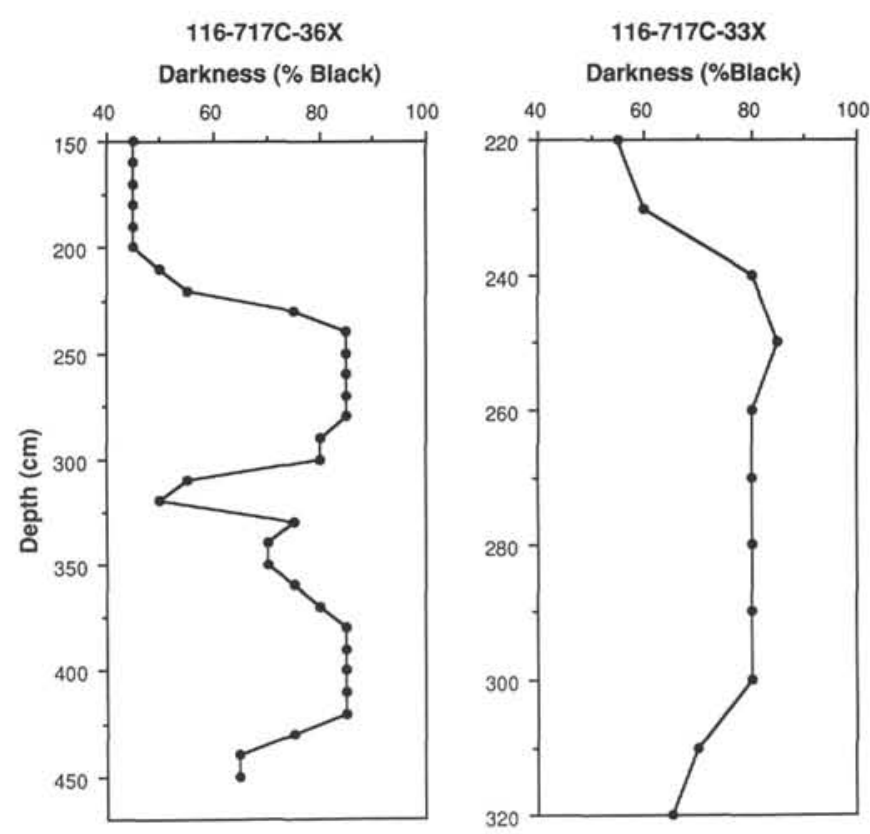

Figure 8. Gray-scale darkness plotted vs, depth in core for the black mud turbidites examined in this study.

surements (compare Figs. 3 and 4 with Fig. 11). The turbidite from Core 116-717C-33X displayed a peak symmetrical about the center of the layer whereas the turbidite from Core 116-717C-36X showed its characteristic increasingdownward shape. These observations imply that the susceptibility signatures recorded from whole cores with the large loop sensor are typical of the entire core and are not artifacts caused either by drilling or the geometry of the sensor. 



Figure 9. Particle-size distributions for the two study turbidites. At top, mean grain size is plotted vs. depth. On the bottom, grain-size histograms are compared for a sample within the study turbidite and a sample from the surrounding sediments. The solid bars represent the black turbidite sample whereas the pattern denotes the other. 

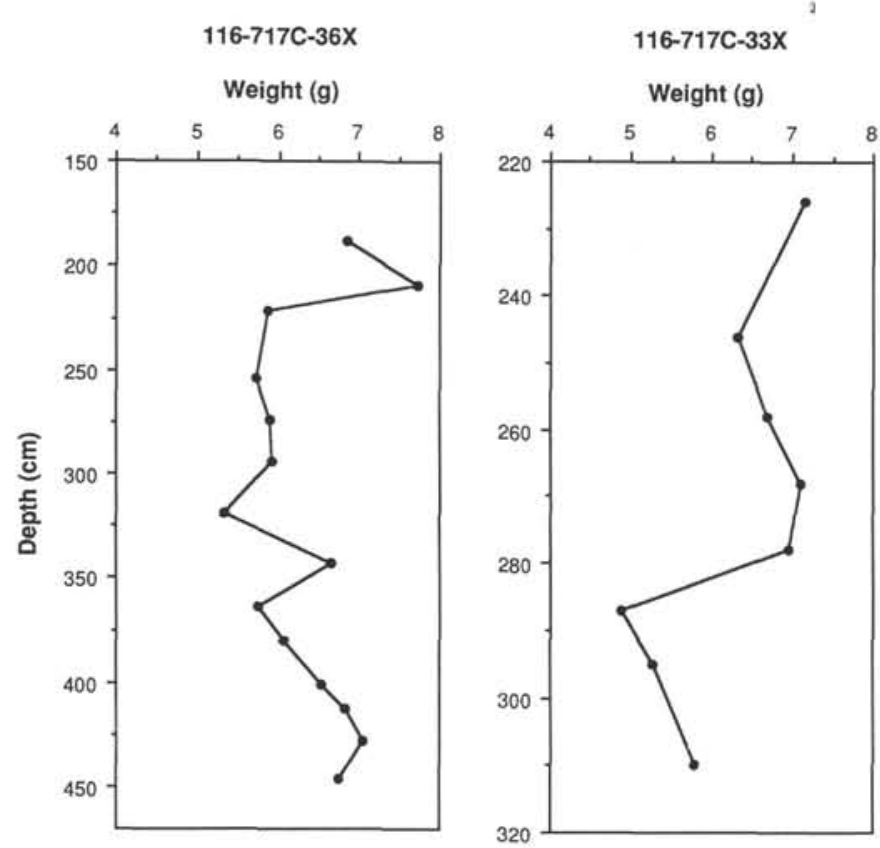

Figure 10. Dry weight plotted vs. depth in core for the study turbidites.
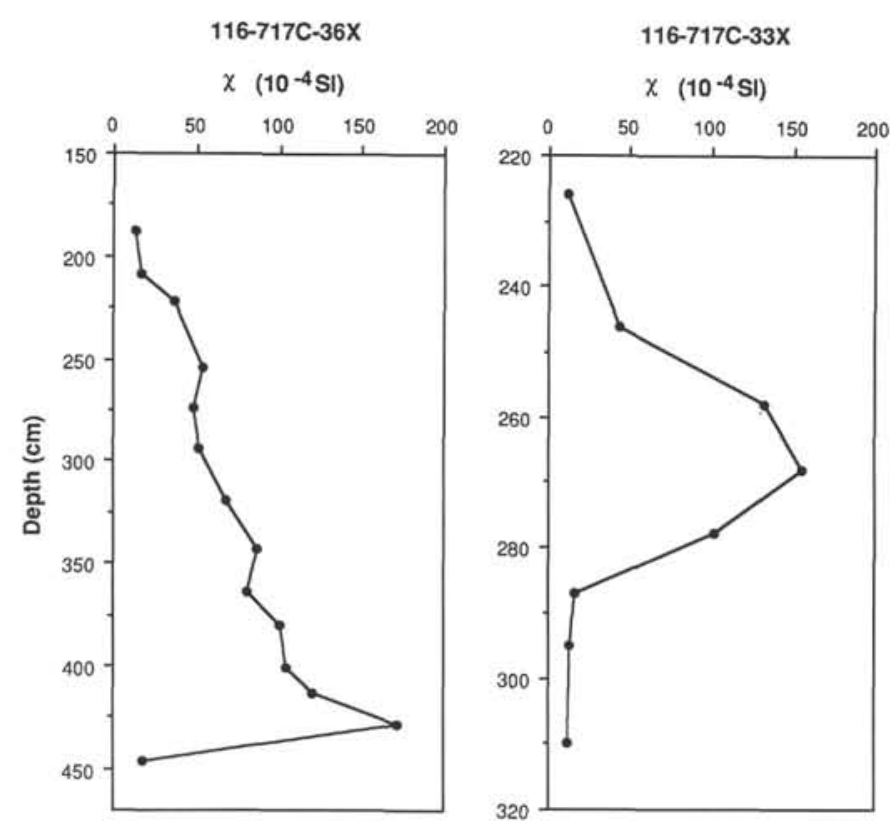

Figure 11. Mass susceptibility plotted vs. depth in core for the study turbidites.

The frequency dependence of susceptibility is sensitive to small magnetic grains in the superparamagnetic (SP) to lower single-domain (SD) size range (Thompson and Oldfield, 1986). In general, the $\chi_{f d}$ values obtained for the study turbidites are small, but those from the Core 116-717C-33X turbidite are somewhat higher and more variable than those from the Core $116-717 \mathrm{C}-36 \mathrm{X}$ turbidite (Fig. 12). $\chi_{f d}$ in the latter averages around $1 \%$ and shows no significant trend with depth, but in the former it increases to over $4 \%$ near the bottom of that layer. These results suggest that the number of SP grains is small, but that there may be a slight increase in their concentration towards the bottoms of some turbidites. Being super- paramagnetic, these grains should only contribute to the susceptibility and not to the magnetic remanences.

\section{Natural Remanent Magnetization}

NRM intensities (Fig. 13) show a range of three orders of magnitude, from $2.6 \times 10^{-7} \mathrm{Am}^{2} \mathrm{~kg}^{-1}$ to $2.03 \times 10^{-4} \mathrm{Am}^{2} \mathrm{~kg}^{-1}$. As expected, the largest values are from within the black mud turbidites. Interestingly, there is not a one-to-one correspondence between the susceptibility and NRM intensity (compare Figs. 11 and 13). The NRM vs. depth curve of the turbidite of Core $116-717 \mathrm{C}-33 \mathrm{X}$ is not as symmetrical as its susceptibility curve. The NRM curve of the other turbidite shows several maxima and minima rather than the steady increase in depth displayed by its susceptibility. Furthermore, the highest NRM was measured from Sample 116-717C-36X-3, 101-103 cm, whereas the highest susceptibility was recorded from Sample 116-717C-36X-3, 128-140 cm (Fig. 13). Perhaps this phenomenon results from varying amounts of overprint, caused by drilling and handling and retained by different parts of the turbidites (Hall and Sager, this volume).

NRM MDF values were markedly different across the turbidite boundaries. Samples from outside the turbidites mostly had high MDF values, whereas those from within had very low values (Fig. 14). All of the black mud turbidite samples from Core 116-717C-33X had MDFs less than $10 \mathrm{mT}$ and all but two of those from Core 116-717C-36X had MDFs less than $20 \mathrm{mT}$. These results imply a difference in the remanence-carrying magnetic minerals inside and outside of the black mud turbidites; low coercivities characterize those within, whereas higher coercivities are typical of those in the surrounding layers. Such a difference could arise because of grain size or composition changes across the turbidite boundaries.

The behavior of the natural remanence during AF demagnetization was variable (Fig. 15). All samples displayed an overprint in the upward direction (negative inclination). Indeed, this was a pervasive feature of most paleomagnetic samples from Leg 116 sediment cores (Hall and Sager, this volume). Similar overprints have been noted on DSDP and other ODP cruises and attributed to exposure of the cores to high magnetic fields around the drill string or other shipboard metal objects (e.g., Keating, 1984; Sager and Hutton, 1986; Backman, Duncan et al., 1988). In most samples, the overprint appears to be removed after demagnetization in fields of $10-20 \mathrm{mT}$ at which point the inclination is close to zero, as expected for sediments deposited near the Equator. However, some samples never reach a stable characteristic direction, or begin to behave erratically at high AF demagnetization steps (Fig. 15). We found it impossible to reliably predict, based upon lithology, appearance, or susceptibility, the demagnetization behavior of the samples. Though many of the samples from outside the turbidites showed stable behavior and many of those from within the turbidites were unstable, there were exceptions. These results imply that the magnetic directions determined from many Leg 116 samples may be spurious.

\section{Artificial Remanences}

The study turbidites stand out in their capacity to acquire both an ARM and SIRM. For both remanence types, samples from within the turbidites retained one to two orders of magnitude higher intensity than samples from surrounding layers (Fig. 16). In both turbidites, the ARM and SIRM curves have similar shapes that are in turn similar to their NRM curves (Fig. 13).

IRM acquisition curves (Fig. 17) also show a significant difference between samples from the study turbidites and surrounding layers. Those from within the turbidites saturate 
116-717C-36X

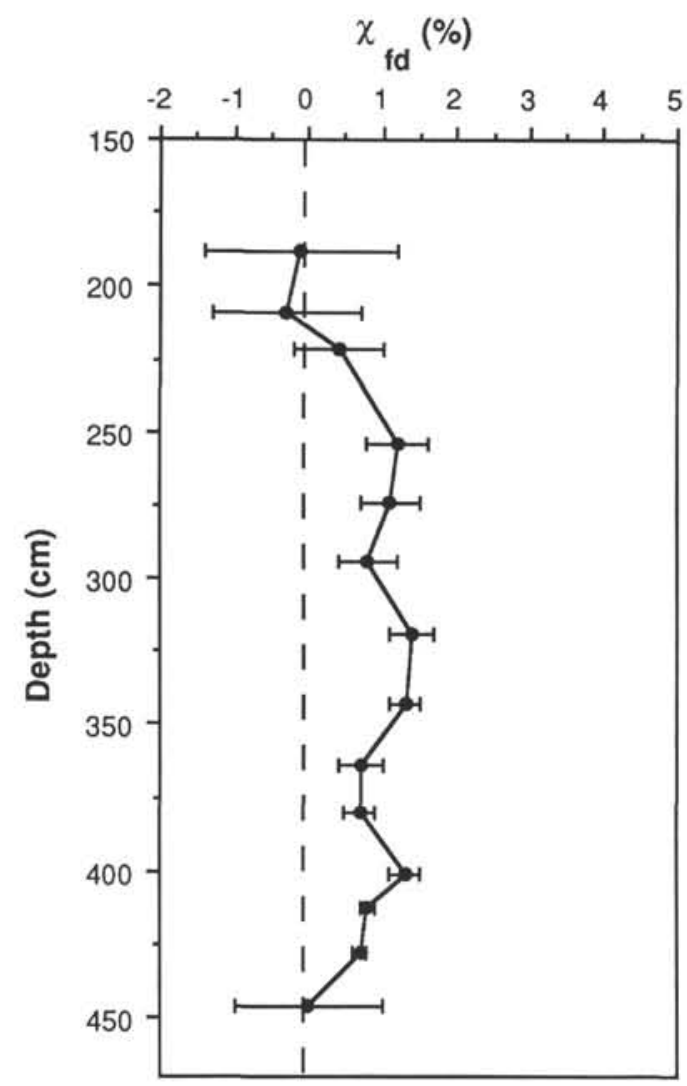

116-717C-33X

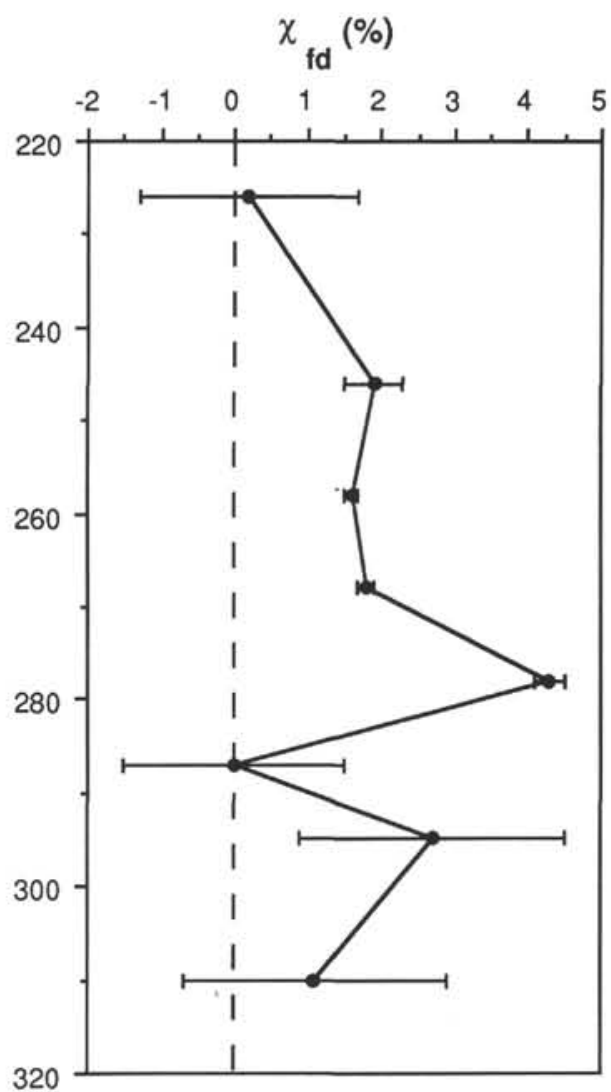

Figure 12. Frequency dependence of susceptibility (see text for explanation) plotted vs. depth in core for the study turbidites. Horizontal bars are estimated errors for $\chi_{f d}$.

in relatively low fields, reaching over $90 \%$ of saturation in fields less than $100 \mathrm{mT}$. On the other hand, samples from outside the study turbidites require much higher applied fields, $1 \mathrm{~T}$ or more, to reach saturation. These results suggest that the former are dominated by a low-coercivity magnetic mineral, such as magnetite, whereas the latter are characterized by a high-coercivity mineral, such as hematite. Looking more closely at the IRM acquisition curve for the low-coercivity sample in Fig. 17, we note that, although it has a steep slope near the origin, indicative of a rapid approach to saturation, a large applied field is required to push it all the way to saturation. This behavior suggests that there may be some high-coercivity magnetic minerals mixed in with the lowcoercivity grains in the study turbidites.

SIRM thermal demagnetization also indicates a mixture of magnetic minerals. The magnetization gradually decays with increasing temperature, indicating that the magnetic minerals have a distributed range of blocking temperatures (Fig. 18). The observations that there is a significant amount of magnetization left above $350^{\circ} \mathrm{C}$ and all but $1 \%-3 \%$ of the magnetization is removed by $575^{\circ} \mathrm{C}$, suggest titanomagnetite as the primary remanence carrier. The distributed character of the blocking temperatures may result from titanium impurities in the magnetite grains, lowering their Curie temperatures below the $580^{\circ} \mathrm{C}$ value characteristic of pure magnetite (McElhinny, 1973).

Other features of the thermal demagnetization curves imply that at least one, if not two, additional magnetic minerals are present, probably in small amounts. First, although the magnetization remaining at $575^{\circ} \mathrm{C}$ is small $(3 \%-5 \%)$, it is still significant and probably indicates the presence of hematite, which has a Curie temperature of $680^{\circ} \mathrm{C}$ (McElhinny, 1973). This finding is consistent with our interpretation of the IRM acquisition curves. Second, the slope of the thermal demagnetization curves increases slightly between about $280^{\circ}$ and $350^{\circ} \mathrm{C}$ (Fig. 18), implying a component with a blocking temperature in that range. Because pyrite is abundant in the organic-rich clay layers in which the study turbidites are found, its remanence-carrying relative, pyrrhotite, with a Curie temperature in the range $280^{\circ}-330^{\circ} \mathrm{C}$ (Strangway, 1970 ; Rochette, 1987), may also be present. However, this feature could also be explained with a concentration of titanomagnetite grains with iron-titanium ratios of about 1 , giving them Curie temperatures in that range.

Comparison of samples from the two study turbidites showed that their IRM acquisition and thermal demagnetization curves are virtually indistinguishable (e.g., Fig. 18). This observation implies that the magnetic mineralogy of the two turbidites, separated by about $30 \mathrm{~m}$ in the stratigraphic column, is very similar. Moreover, it suggests that the composition of the sediment source changed very little during the deposition of the clay and mud layers from which these turbidites were sampled.

\section{Magnetic Grain Sizes}

By successively imparting both an ARM and SIRM to our samples and observing their demagnetization behavior, it was possible to apply several tests to our samples to investigate magnetic grain sizes and their variations. We performed a modified Lowrie-Fuller test (Johnson et al., 1975) by compar- 
116-717C-36X NRM (SI)
116-717C-33X

NRM (SI)

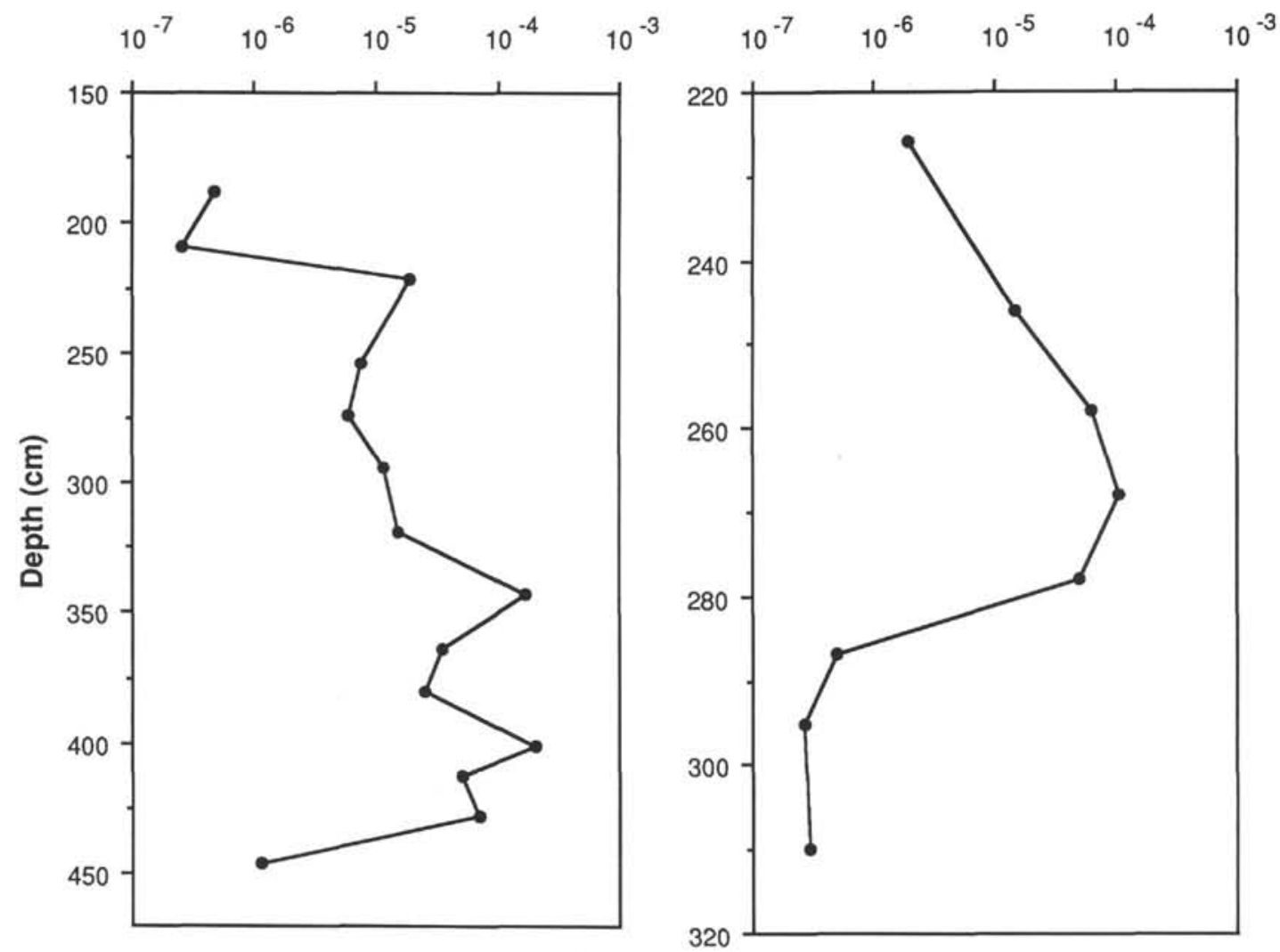

Figure 13. Natural remanent magnetization (NRM) intensity plotted vs. depth in core for the study turbidites. The horizontal scale is logarithmic.
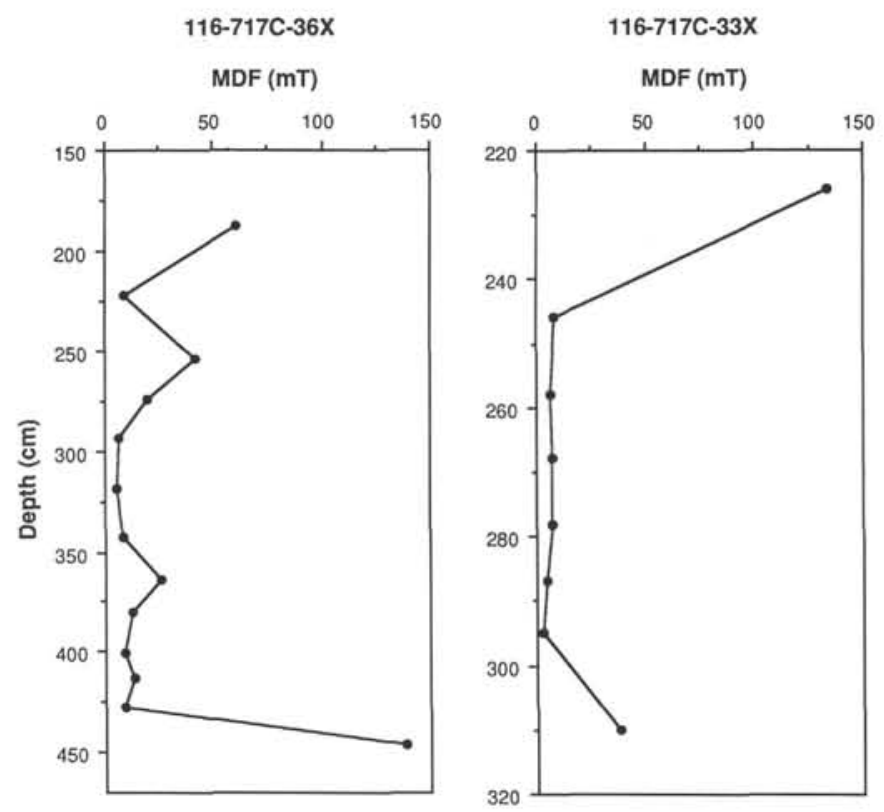

Figure 14. Median destructive field (MDF) plotted vs. depth in core for the two study turbidites. ing the demagnetization behavior of the ARM and IRM. The basis of this test is that for SD and pseudo single-domain (PSD) magnetite grains the ARM is more resistive to AF demagnetization than is the SIRM, but for multidomain grains (MD) the converse is true.

Figure 19 shows ARM and IRM demagnetization curves typical of samples in and out of the study turbidites. Samples outside the turbidites do not show a clear separation of ARM and IRM at low to moderate demagnetization steps, so that for them the Lowrie-Fuller test could not be applied. This is probably because the test was devised for magnetite, but hematite is the likely remanence-carrier in these sediments. On the other hand, samples within the study turbidites appear to be dominated by magnetite and there is a separation of the ARM and IRM demagnetization curves at low to moderate AF steps (Figs. 19 and 20). The curves do not remain separated, as expected for samples of pure magnetite (Johnson et al., 1975), but instead they cross at high AF steps, usually about $50-60 \mathrm{mT}$. This behavior is probably the result of the combination of low-coercivity magnetite and high-coercivity hematite. At low AF demagnetization steps, the magnetite behavior is dominant, but at high AF steps the hematite becomes important. Nonetheless, the difference in ARM and IRM demagnetization implies that the magnetite within the turbidites is within the SD or PSD size range (Fig. 20).

Several authors have used ARM and SIRM and their ratios with susceptibility to detect changes in magnetic grain size (Banerjee et al., 1981; King et al., 1982; Thompson and Oldfield, 1986). Both the ARM and SIRM intensities are highly sensitive to the grain size, particularly in the SD and PSD size range, being 

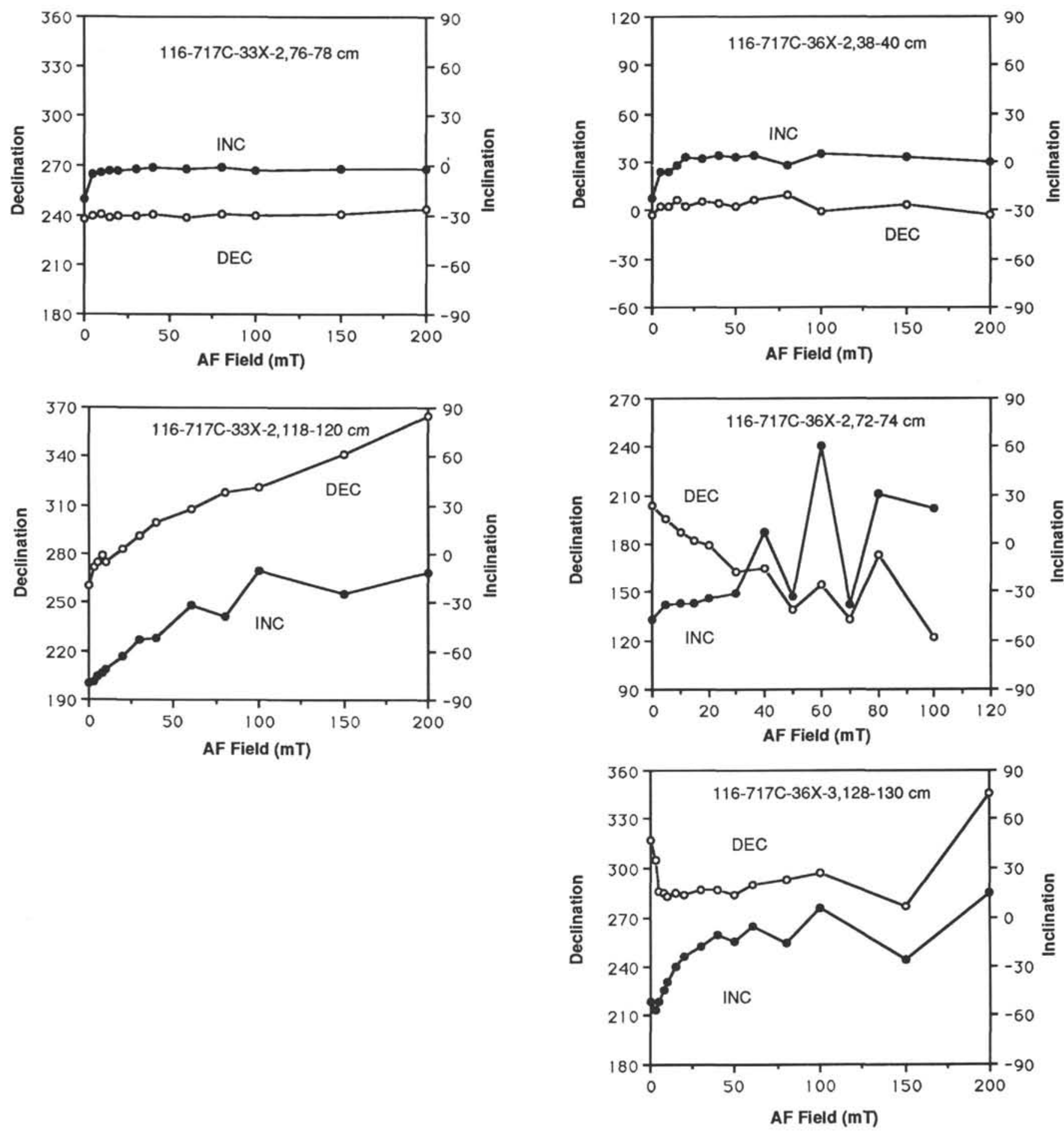

Figure 15. Variation of paleomagnetic inclination and declination at progressive alternating field (AF) demagnetization steps for samples from the study turbidites and surrounding layers. Samples from Core 116-717C-33X are on the left and from 116-717C-36X, on the right.

strongest for SD and decreasing toward the larger PSD to MD grain sizes. Susceptibility, on the other hand, is less sensitive to grain size, with variations in susceptibility controlled mainly by differences in magnetic mineral concentration (Thompson and Oldfield, 1986). Consequently, ARM and SIRM normalized by susceptibility have been used to minimize concentration effects while highlighting grain-size variations.

Two tests of grain size and concentration variations have been devised using plots of either SIRM or ARM vs. susceptibility. Thompson and Oldfield (1986) suggest using a bilogarith- mic graph of SIRM intensity vs. susceptibility, whereas Banerjee et al. (1981) and King et al. (1982) utilized a bilinear plot of ARM intensity vs. susceptibility. On both type of plots, samples having greater concentrations of magnetite are located farther from the origin and samples with equal grain sizes should plot along straight lines. In the former, the equal grain size lines have a slope of unity with the larger grain sizes having lesser SIRM $/ \chi$ ratios (Thompson and Oldfield, 1986), but in the latter the lines of equal grain size radiate from the origin, with the larger grain sizes having smaller slopes (King et al., 1982). 
116-717C-36X

SI

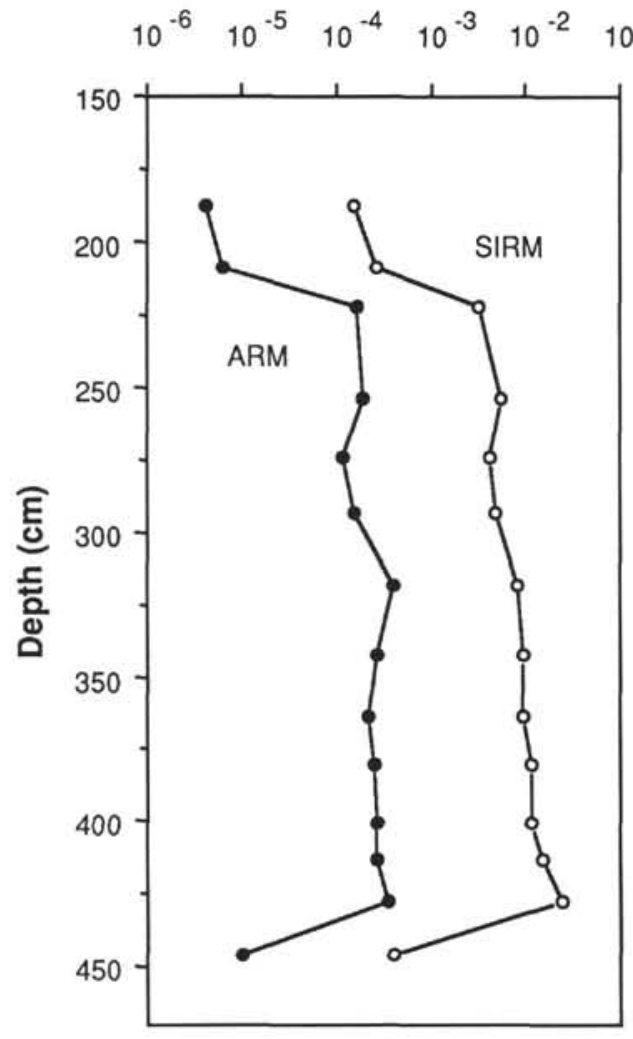

116-717C-33X

SI

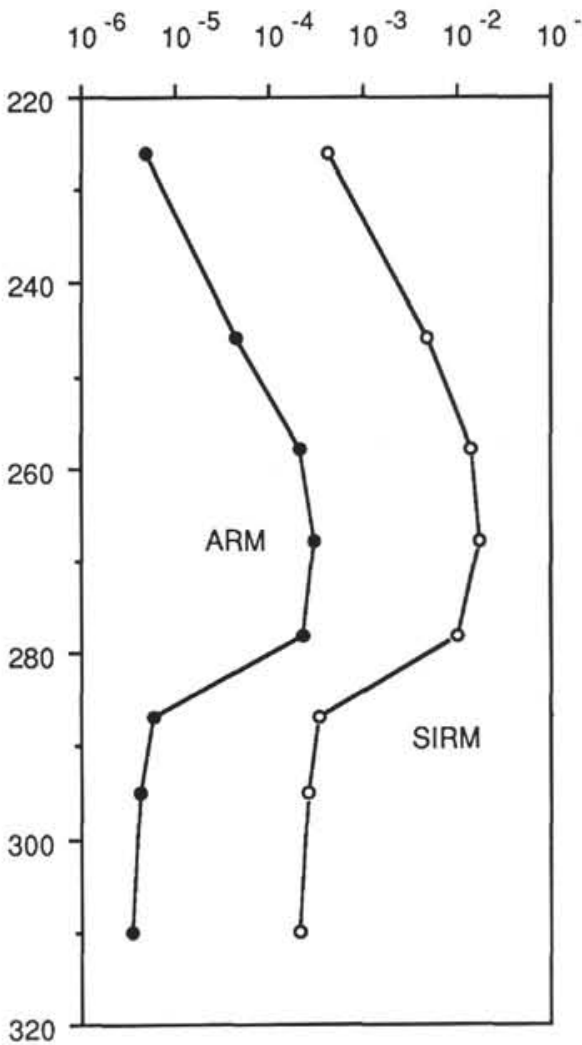

Figure 16. Intensity of artificial remanences, anhysteretic remanent magnetization (ARM), and saturation isothermal remanent magnetization (SIRM), plotted vs. depth in core for the study turbidites. The horizontal scale is logarithmic.

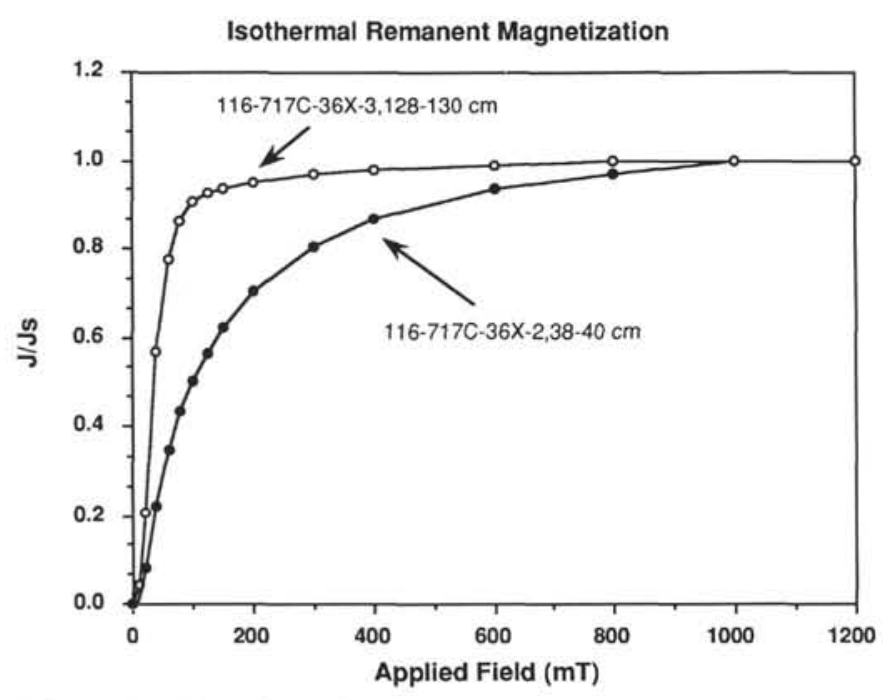

Figure 17. Normalized isothermal remanent magnetization (IRM) acquisition curves for a sample from the Core 116-717C-36X black mud turbidite $(116-717 \mathrm{C}-36 \mathrm{X}-3,128-130 \mathrm{~cm})$ and a sample from the layer above $(116-717 \mathrm{C}-36 \mathrm{X}-2,38-40 \mathrm{~cm}) . \mathrm{J} / \mathrm{Js}$ is the magnetization normalized by the SIRM value.

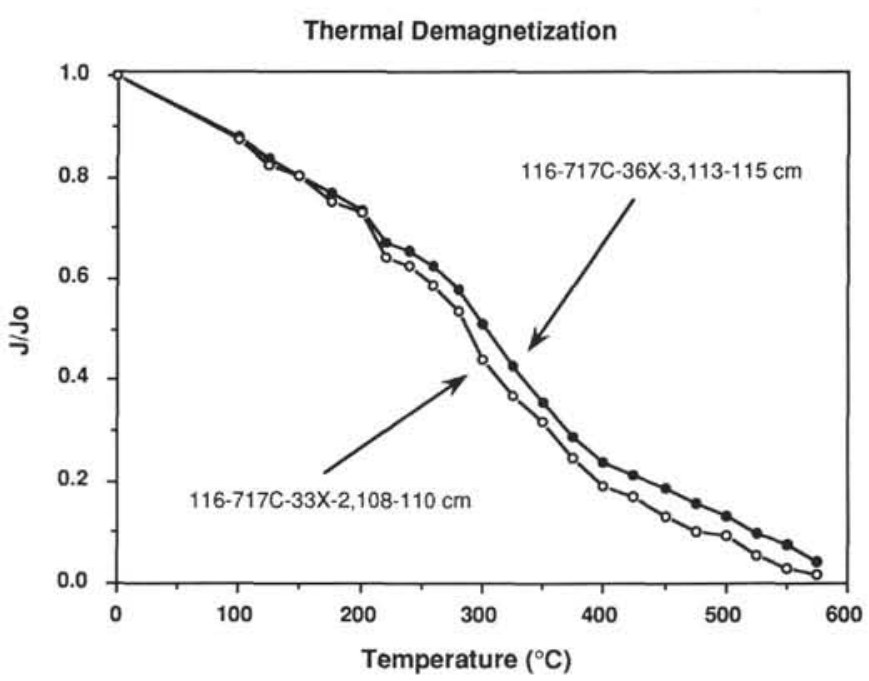

Figure 18. Normalized step-wise thermal demagnetization curves for two samples from the studied black mud turbidites.

On both types of plot, samples from the study turbidites are distinct from those of surrounding layers (Figs. 21 and 22). The points representing samples outside the turbidites suggest that they have the lowest magnetic mineral concentrations and the largest grain sizes; however, as both types of test were devised primarily for magnetite, these grain-size estimates are 

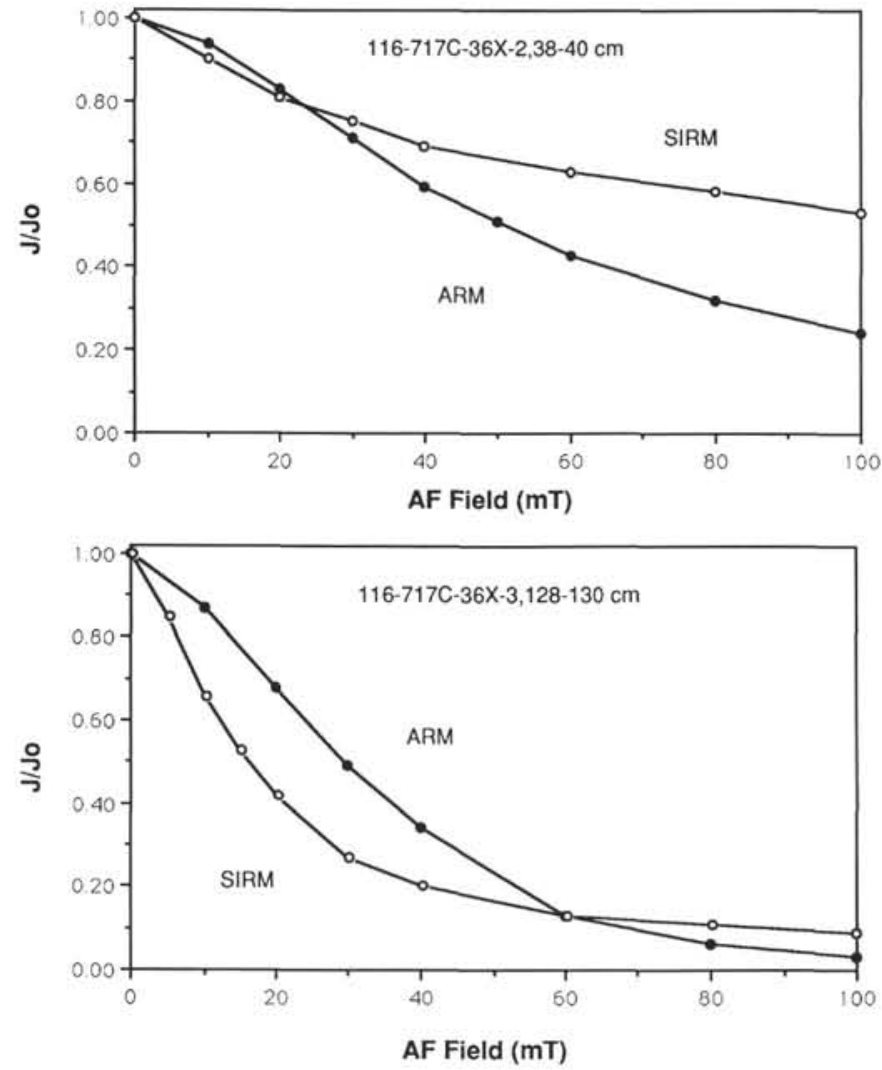

Figure 19. AF demagnetization curves for artificial remanences imparted to two samples, one from the black mud turbidite in Core $116-717 \mathrm{C}-36 \mathrm{X}$ (bottom) and the other from the layer above (top). Note that the sample from the black mud turbidite shows a separation of the ARM and SIRM demagnetization curves at low to moderate AF steps whereas the other sample does not.

probably inaccurate. Nevertheless, the points representing the turbidite samples in both plots suggest finer grain sizes and greater concentrations. The implications of the two tests for the black mud turbidite samples are more likely to be correct because our other findings imply that magnetite is the dominant magnetic mineral in these samples.

The turbidite samples in both graphs display linear trends: in the SIRM-susceptibility plot, the slope is 0.84 with a correlation coefficient of 0.98 , and on the ARM-susceptibility plot the slope is 15.2 with a correlation coefficient of 0.73 . Furthermore, in both cases the samples with the highest intensities plot farthest from the origin. For the Core 116717C-33X turbidite, these are the samples from the middle of the layer, whereas for the Core 116-717C-36X turbidite, these are the samples from the bottom of the layer (Figs. 21 and 22). This suggests that it is variations in the concentration of magnetite that gives these turbidites their susceptibility signatures. The SIRM-susceptibility plot (Fig. 21) implies that this concentration is between $0.01 \%$ and $0.1 \%$ magnetite by volume. Interestingly, this magnitude of concentration increase translates into a weight increase of about $0.6 \mathrm{~g}$ for a $6-\mathrm{g}$ sample. This is close to the observed weight increase with depth in the two study turbidites (Fig. 10) and implies that much of the weight increase of these sediments may arise from the concentration of magnetic grains.

The grain sizes indicated by the two plots differ considerably. The SIRM $/ \chi$ ratio is consistent with a magnetic grain size of 4-10 $\mu \mathrm{m}$ (Fig. 21); however, the sample positions on the ARM vs. susceptibility plot imply extremely fine grain sizes,
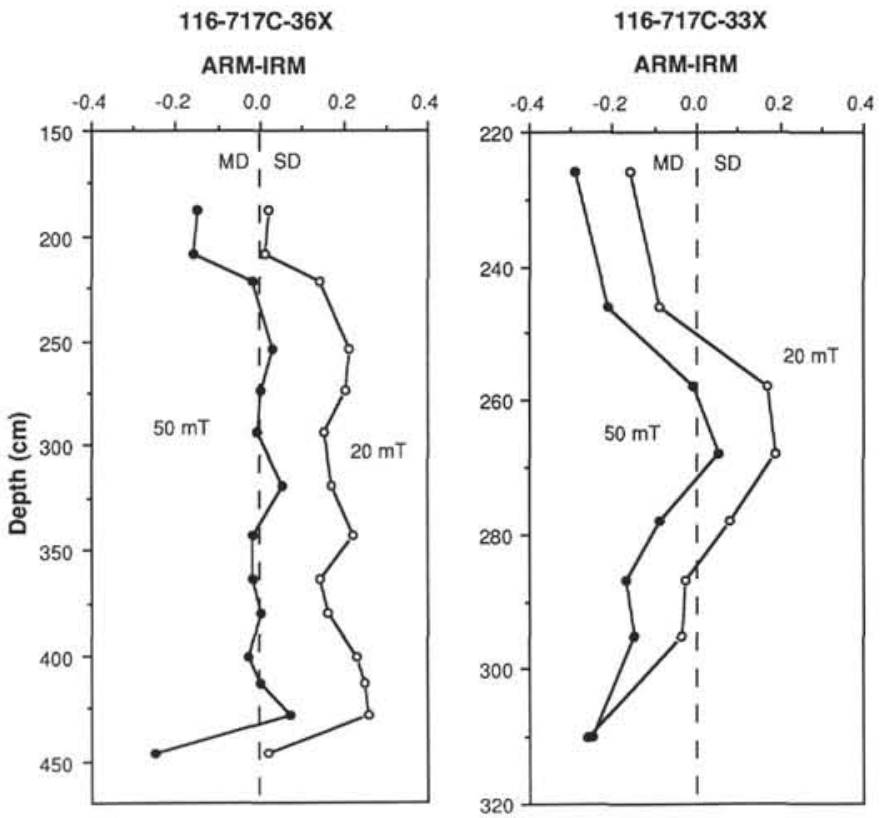

Figure 20. Modified Lowrie-Fuller test (Johnson et al., 1975) for the two study turbidites. The quantity on the horizontal axis in both plots is the difference between the normalized ARM intensity and the IRM intensity remaining at the same AF demagnetization step; it is shown for both the 20 - and $50-\mathrm{mT}$ demagnetization steps. When this quantity is positive, the magnetic grains are acting as single-domain (SD) or pseudo-single-domain (PSD) grains, but if the quantity is negative, then a multidomain (MD) behavior is indicated.

less than $0.1 \mu \mathrm{m}$ in diameter (see King et al., 1982). Similarly, the two remanence ratios appear to give conflicting clues about grain-size variations.

The marked linearity of the sample points on the SIRM vs. susceptibility plot (Fig. 21) imply that the grain size does not change much within the turbidite. However, the small deviation of the samples from a unit slope in this plot implies that the grain size decreases slightly with increasing concentration and magnetic intensity. For the Core 116-717C-36X turbidite this suggests a fining-downward sequence, but a trend for the samples from the Core 116-717C-33X turbidite is not obvious because of the small number of samples. Though there appears to be a linear trend of sample points on the ARM vs. susceptibility plot (Fig. 22), the best-fit line does not radiate from the origin as expected (King et al., 1982). This could be interpreted as indicative of a wide range of magnetic grain sizes or perhaps that this test is inappropriate for these samples.

Plots of SIRM $/ \chi$ and ARM $/ \chi$ vs. depth (Fig. 23) should add additional insight to relative changes in grain size within the study turbidites. Indeed, both ratios are elevated in the turbidites and display interesting trends within these layers. In the Core $116-717 \mathrm{C}-33 \mathrm{X}$ turbidite, $\mathrm{SIRM} / \chi$ remains relatively constant at about 11,000 whereas $\mathrm{ARM} / \chi$ increases downward from 103 to 219 . Even more interesting are the trends in the Core 116-717C-36X turbidite within which SIRM $/ \chi$ increases downward from about 9,000 to 13,550 , but $A R M / \chi$ decreases from about 441 to 200 . Moreover, Sample 116-717C-36X-3, $19-21 \mathrm{~cm}$, at $319 \mathrm{~cm}$ depth, has a significantly higher $\mathrm{ARM} / \chi$ value than any other sample.

Typically, both types of curve would be interpreted in the same fashion, with increasing SIRM $/ \chi$ and $\mathrm{ARM} / \chi$ indicating a shift to finer magnetic grains; however, the divergent trends displayed by these ratios in Figure 23 suggest that this 


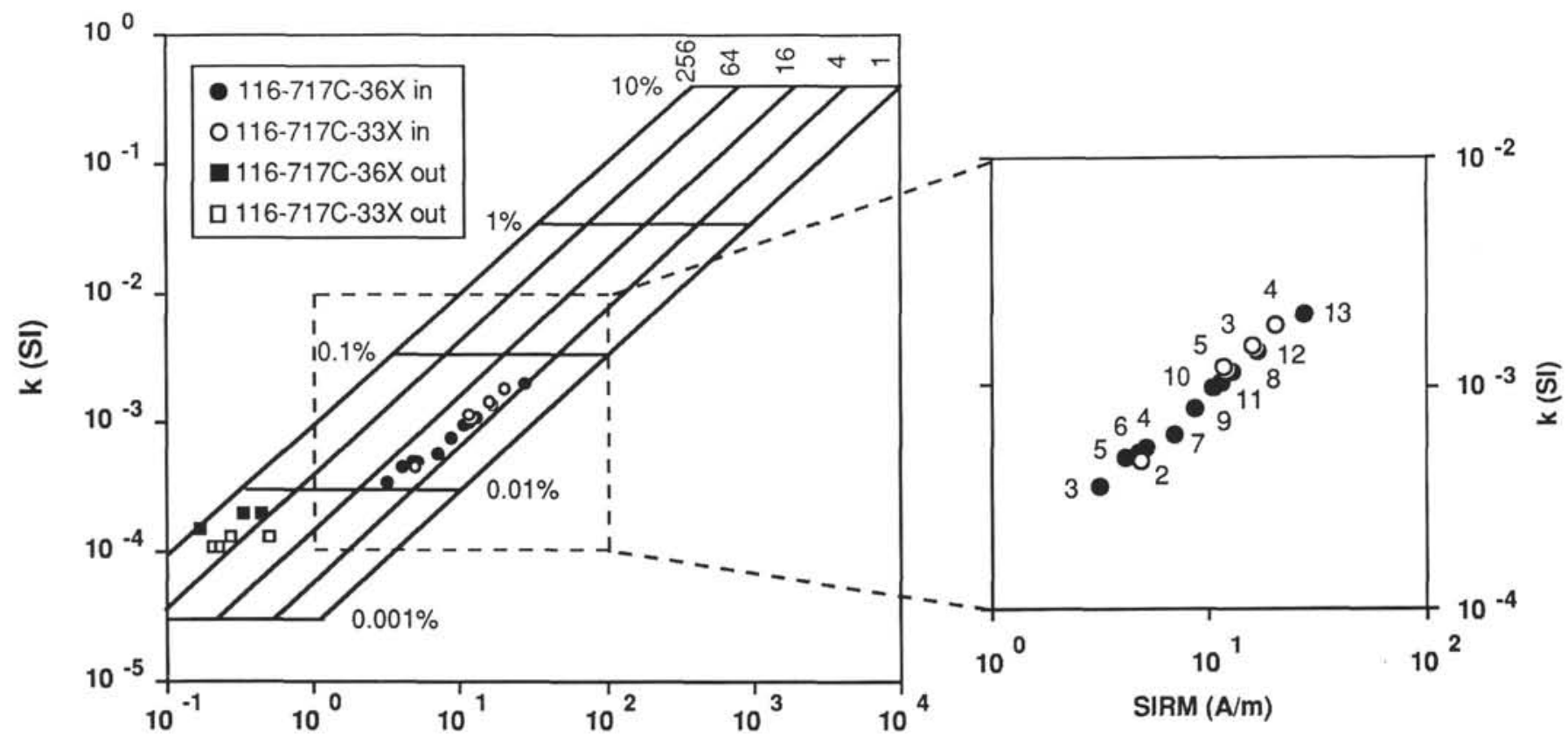

$\operatorname{SIRM}(\mathbf{A} / \mathrm{m})$

Figure 21. Bilogarithmic plot of volume susceptibility, k vs. SIRM. Samples from within the study turbidites are shown by circles, whereas those from surrounding layers are shown by squares. Sloping lines show equal grain size and horizontal lines show increasing volume concentration (from Thompson and Olfield, 1986). Plot at right is a close-up of the turbidite samples. The numbers are sample identifiers; samples are numbered sequentially from the top of each sampled section. For example, "2" represents either Sample 116-717C-33X-2, 96-98 cm, or 116-717C-36X-2, $59-61 \mathrm{~cm}$.

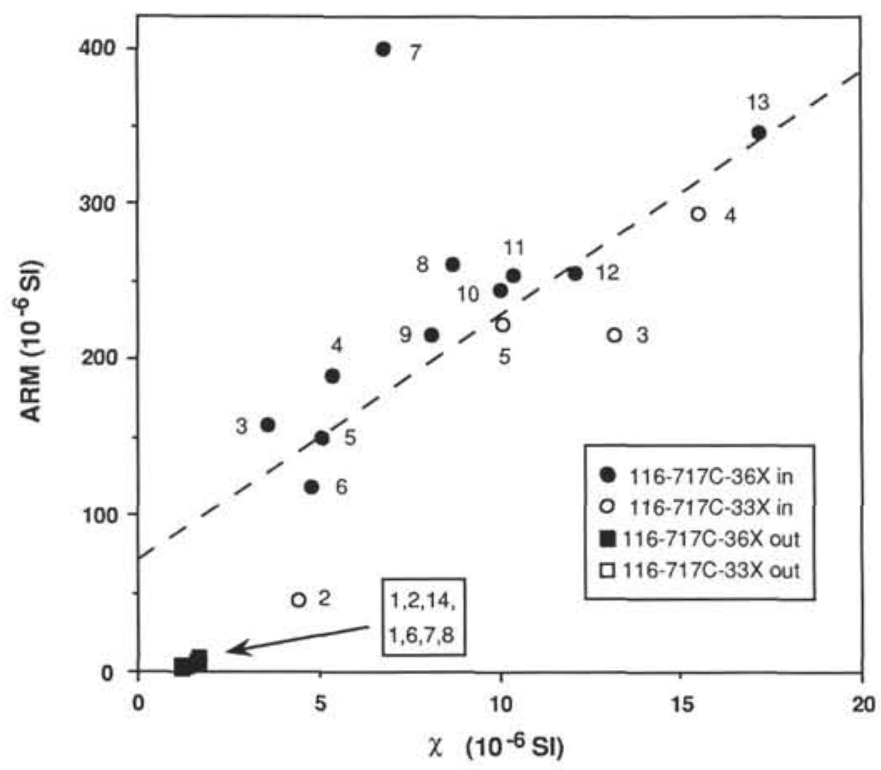

Figure 22. Plot of ARM intensity vs. mass susceptibility. Circles represent samples from the study turbidites and squares denote samples from surrounding layers. The dashes show the best leastsquares line fit to the circle data points. Sample numbers are the same as in Fig. 21. interpretation may not be so simple. In the Core 116717C-33X turbidite, constant $\operatorname{SIRM} / \chi$ implies a constant magnetic grain size, but $\mathrm{ARM} / \chi$ increases with depth indicating a fining-downward sequence. Similarly, the increasing values of $\operatorname{SIRM} / \chi$ with depth in the Core 116-717C-36X turbidite point to a fining-downward sequence, whereas the decreasing values of $\mathrm{ARM} / \chi$ with depth imply the opposite.

\section{Electron Microscopy}

Under the SEM, the detrital nature of the turbidite sediments is clear. Their constituent grains are angular to subrounded in texture and have sizes usually in the range of 1-20 $\mu \mathrm{m}$. Visual examination and EDX spectra show that quartz, plagioclase, potassium feldspar, biotite, and muscovite are common. Iron-titanium oxides, anorthite, pyrite, calcite, and pyroxene grains were also noted.

In the magnetic separates there is a concentration of iron-titanium oxide grains. EDX spectra of these grains show significant titanium as well as iron peaks. In their pure form, magnetite $\left(\mathrm{Fe}_{3} \mathrm{O}_{4}\right)$ and hematite $\left(\mathrm{Fe}_{2} \mathrm{O}_{3}\right)$ are iron oxides; however, both form solid solution series with iron-titanium oxides, the former with ulvospinel $\left(\mathrm{Fe}_{2} \mathrm{TiO}_{4}\right)$ and the latter with ilmenite $\left(\mathrm{FeTiO}_{3}\right)$. Furthermore, varying degrees of oxidation can push a titanomagnetite toward an ilmenohematite, so intermediate compositions are possible (McElhinny, 1973). Because the dominant magnetic properties of the turbidite samples are consistent with magnetite, we think that these grains are titanomagnetites. Additionally, the heights of the iron and titanium peaks in the EDX spectra suggest that their compositions are somewhere in the middle of the solid solution series with considerable variation. The fact that the Curie temperature of titanomagnetite is dependent on the irontitanium ratio, ranging from about $-200^{\circ} \mathrm{C}$ for pure ulvospinel 
116-717C-36X

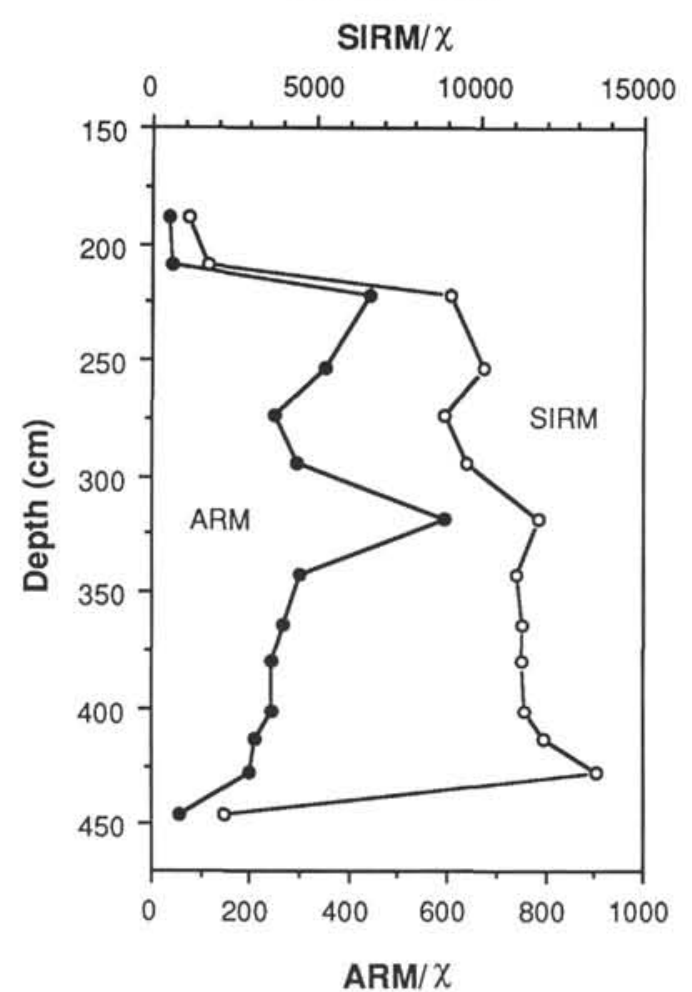

116-717C-33X

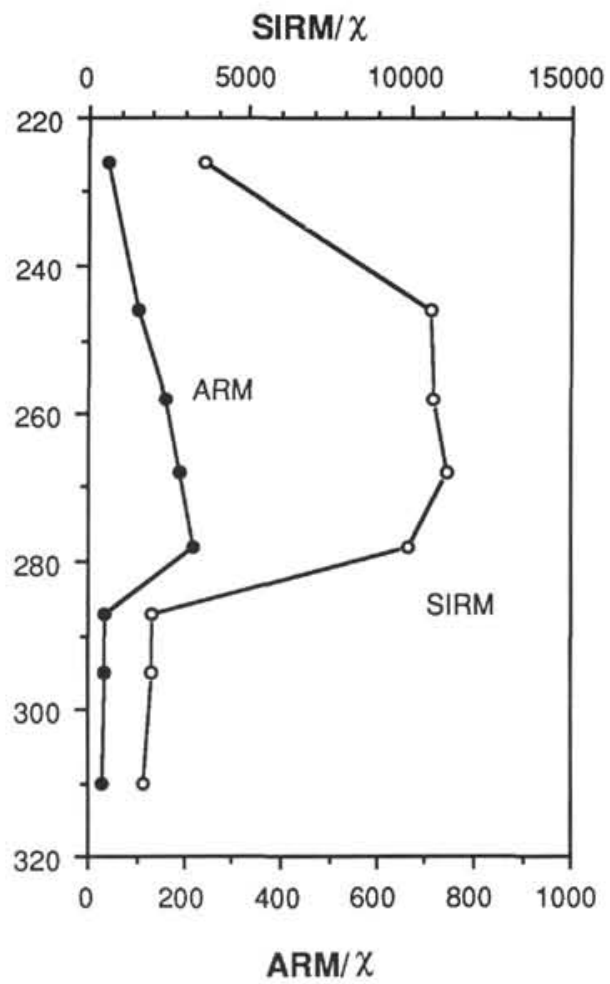

Figure 23. Plot of SIRM/ $\chi$ and ARM/ $\chi$ vs. depth in core for the two study turbidites.

to $575^{\circ} \mathrm{C}$ for pure magnetite (McElhinny, 1973), seems to explain our observation that the blocking temperatures of these samples are distributed with a major component in the $200^{\circ}-350^{\circ} \mathrm{C}$ range.

The titanomagnetite grains are also angular to subrounded and generally have sizes in the $8-10-\mu \mathrm{m}$ range, consistent with the $\mathrm{SIRM} / \chi$ ratio (Fig. 23), with occasional grains up to about $20-25 \mu \mathrm{m}$ in length (Fig. 24). These grains range from more-orless equant to elongated with axial ratios up to about $2: 1$. Additionally, they are often tabular, with thicknesses of 3-5 $\mu \mathrm{m}$ and width to thickness ratios of about 2 to 3 . A few grains contain thin plates with trellis structures that appear to be ilmenite lamellae. These features form during the cooling of a high titanium content magnetite when the grain exsolves into unstable ulvospinel and magnetite, and the ulvospinel converts to ilmenite (McElhinny, 1973). The observation of these lamellae supports our conclusion that the grains are titanomagnetites.

No other types of magnetic grains were noted within the magnetic concentrates. In particular, we saw no grains of the fine sizes implied by the ARM-susceptibility plot (Fig. 22); however, extremely fine grains, much smaller than a micrometer, would probably be missed by SEM examination because they are at or below the resolution limit of the microscope we used. Additionally, the crude technique we used to separate the magnetic fraction may have been biased, capturing mainly the larger, more magnetic titanomagnetite grains and leaving the weaker hematite and fine titanomagnetite grains behind.

\section{DISCUSSION}

Our investigation of the magnetic properties of organic-rich black-gray biogenic mud turbidites from Hole $717 \mathrm{C}$ suggests that their remanent magnetism is mainly a result of titanomagnetite grains mixed with some hematite. Titanomagnetite behavior dominates the magnetic properties of the black mud turbidite samples. They are characterized by high values of $\chi$, NRM, ARM, SIRM, ARM $/ \chi$, and SIRM $/ \chi$ (Figs. 11, 13, 16, 22). Additionally, they display distributed but moderatelyhigh blocking temperatures (Fig. 18), with a significant component remaining at temperatures higher than $300^{\circ} \mathrm{C}$, which is almost completely destroyed at $580^{\circ} \mathrm{C}$, the Curie temperature for magnetite. However, the most distinctive property is the low coercivity implied by their rapid approach to saturation in low strength applied fields (Fig. 17) and low MDF values (Fig. $14)$, behavior which is typical of magnetite.

Hematite may also be present in these turbidites, implied by the reluctance of the turbidite samples to reach complete saturation, even in moderate strength applied fields (Fig. 17). The greenish gray biogenic sediments surrounding the darkgray mud turbidites also contain hematite. Samples from these layers, however, show no indication of magnetite, so the hematite dominates their magnetic properties. Their most characteristic property is high coercivity, shown high MDF values (Fig. 14) and a gradual approach to saturation (Fig. 17).

Magnetic tests used to estimate the size of the titanomagnetite grains that give the black mud turbidites their distinctive magnetic signatures gave conflicting results. SIRM-susceptibility ratios imply a relatively restricted range of grain sizes around $4-\mu \mathrm{m}$ whereas ARM-susceptibility ratios indicate very fine grains, less than a micrometer in size. What is more, these ratios imply different trends of grain size variation with depth. For example, SIRM $/ \chi$ increases downward in the Core 116717C-36X turbidite, but ARM/ $\chi$ decreases downward (Fig. 23). The former could be interpreted to indicate a downward decrease in grain size and the latter, the opposite (King et al., 1982; Thompson and Oldfield, 1986). Unfortunately, none of the other magnetic grain size tests resolves this conundrum. 

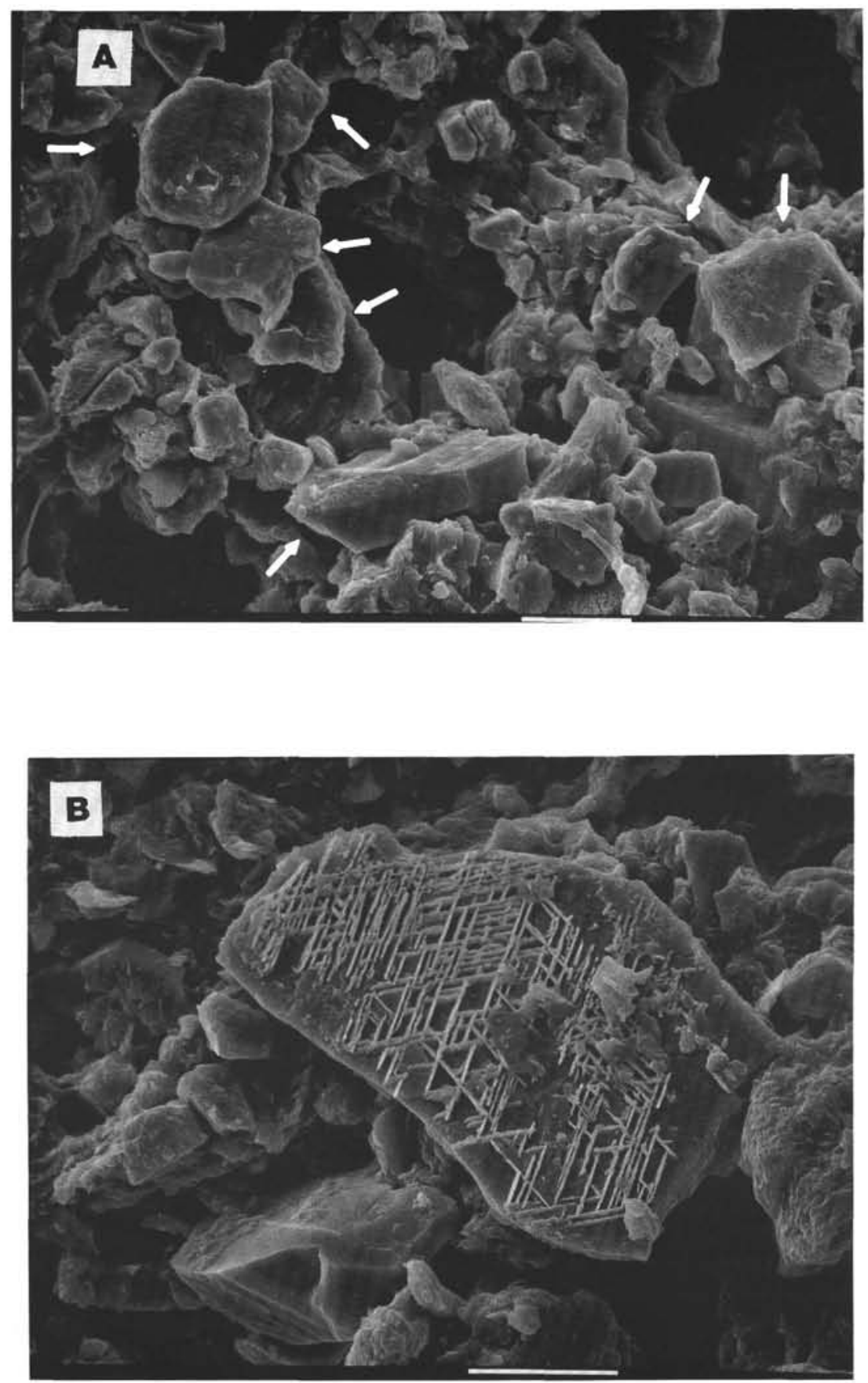

Figure 24. SEM photomicrographs of magnetic concentrates from Sample 116-717C$33 \mathrm{X}-2,118-120 \mathrm{~cm}$. A. Arrows identify titanomagnetite grains. B. Large titanomagnetite grain displaying ilmenite lamellae in a trellis exsolution pattern. The scale bar is $10 \mu \mathrm{m}$.

The modified Lowrie-Fuller test indicates mainly SD or PSD grain behavior, but these properties have been attributed to a wide range of grain sizes. This range varies considerably depending on the aspect ratio of the grains, but several studies suggest about $0.05-0.1 \mu \mathrm{m}$ to $10-20 \mu \mathrm{m}$ for equidimensional magnetite SD particles (Parry, 1965; Dunlop, 1973; 1986; McElhinny, 1973; Butler and Banerjee, 1975; Day et al., 1977; Moskowitz and Banerjee, 1979). Measurements of $\chi_{f d}$ are also inconclusive. These values are small, but nonzero, implying that the samples contain fine SP grains, but that the dominant magnetic minerals are probably non-SP. However, unlike $\mathrm{SIRM} / \chi$ and $\mathrm{ARM} / \chi$, the $\chi_{f d}$ values in the Core $116-717 \mathrm{C}-36 \mathrm{X}$ turbidite show no discernible trend with depth (Fig. 12). Finally, magnetic separates examined with a SEM showed many titanomagnetite grains of the size predicted by SIRM $\chi$, but this in itself is also inconclusive because extremely fine grains might have escaped the separation technique or have been invisible to the SEM.

A complete resolution of the grain-size puzzle is beyond the scope of this paper. We know that titanomagnetite grains around $10 \mu \mathrm{m}$ in size are present in the samples, abundant, and apparently rather magnetic. These grains probably dominate the magnetic behavior of the black mud turbidites. We suspect that a fine fraction may also be present, but it is 
difficult to separate and examine. Our results show that the interpretation of $\mathrm{SIRM} / \chi$ and $\mathrm{ARM} / \chi$ in terms of grain-size variations is not straightforward. Evidently variables that we were unable to quantify or control affected the ARM and SIRM in different ways. Perhaps in sediments with both large and fine magnetite grains, the SIRM responds to the former and the ARM to the latter. These differences, if understood, could be useful tools for assessing the magnetic grain properties of sediments.

The SIRM and ARM vs. susceptibility plots did, however, answer our question about the cause of the large susceptibility peaks associated with the black mud turbidites. The samples that correspond to the highest susceptibility also generally have the strongest SIRM and ARM and plot farthest from the origin of either graph (Figs. 21 and 22). This implies that they have the largest volume concentrations of magnetite; the least concentration indicated is about $0.01 \%$ and the largest is about $0.1 \%$ (Fig. 21). Thus, the shape of the susceptibility-depth curve recorded from the black mud turbidites appears to be controlled by the magnetite concentration, an observation in agreement with those made by other authors studying different sediments (e.g., Mullins, 1977; Thompson and Morton, 1979; Thompson et al., 1980).

These observations give us a basis for interpreting the shapes of the peaks noted in the reconnaissance magnetic susceptibility measurements. The susceptibility peaks are caused primarily by a marked increase in the concentration of titanomagnetite grains. The distribution of these grains is likely to be affected by at least two major factors. First, magnetite and hematite have greater densities than crustal silicates, about $5000 \mathrm{kgm}^{-3}$ vs. $2500-3300 \mathrm{kgm}^{-3}$, and are thus likely to sink to the bottom of a density stratified slurry of sediments. On the other hand, because the titanomagnetite grains have sizes in the middle of the particle-size range of these sediments and because their shapes are often tabular, turbulence in the water column may support them after some of the larger and more rounded grains have already settled.

With this as a model we can speculate about the shapes of the susceptibility peaks. In the ramp-shaped, increasingdownward class of turbidites, the magnetic minerals may have the chance to settle preferentially to the bottom of the layer and be deposited first. However, in the symmetric, bellshaped class, the magnetic minerals may be held in suspension longer, perhaps because of greater current velocity, and are not deposited until the middle of the turbidite layer. The ramp-shaped, decreasing-downward class might originate by a lateral migration of the current. A low concentration of magnetic grains are deposited at the edge of the turbidite but the concentration builds as the center of the current moves toward the site. Lastly, the double and multipeaked class of turbidites may form their characteristic shapes as packets of magnetic minerals are deposited either because they are not uniformly distributed throughout the turbidite, because of velocity variations of the current, or perhaps as a result of reworking of the sediments.

The magnetic properties of the black mud turbidites are also a potential clue as to their origins. The AF and thermal demagnetization properties of the samples from these sediments are virtually identical to those of samples from the Deccan, Rajmahal, and Sylhet flood basalts (McDougall and McElhinny, 1970; Talukdar and Murty, 1971; Verma and Pullaiah, 1971; Wensink, 1973; Courtillot et al., 1986). Samples from these basalts generally have distributed blocking temperatures ranging from $200^{\circ}$ to $580^{\circ} \mathrm{C}$ and low MDFs of $2.5-20 \mathrm{mT}$. Furthermore, titanomagnetite with minor amounts of hematite have been identified as the remanence-carrying minerals in the Deccan basalts (Courtillot et al., 1986).
We think that the Deccan basalts are the probable source for the magnetic minerals in the black turbidites for two reasons. First, the Deccan basalts cover a vast area, far larger than the other Indian flood basalts, and thus they should produce a large volume of sedimentary particles. Second, the cored Leg 116 sediments generally fall into two categories, greenish muds and gray silts, the former associated with the Indian subcontinent and the latter with the Himalayan front and Ganges-Brahmaputra river system (Cochran, Stow, et al., 1989; Yokoyama et al., this volume). The weathering products of the Rajmahal and Sylhet basalts should be incorporated into the massive amounts of sediments transported to the Bengal Fan by the Ganges-Brahmaputra river system as they are within its drainage basin. However, particles weathered from the Deccan basalts should be carried by several rivers to the eastern shelf of the Indian subcontinent, the source region for the greenish mud layers in which the black mud turbidites are found.

The magnetic variations of the black mud turbidites also suggest an interplay of sedimentological processes within the source region. Not all of the black turbidites cored on Leg 116 yielded large susceptibility peaks. This observation implies that the titanomagnetite grains and the organic matter that gives these layers their distinctive shade are either from different source regions or become separated at some stage. Perhaps the titanomagnetite grains are concentrated into deposits within the organic-rich sediments and are not tapped by every mud turbidite.

Another interesting facet of this problem is the lack of susceptibility peak correlation between Sites 717 and 719, separated by only $3.2 \mathrm{~km}$. A between-hole comparison was made of corresponding parts of the susceptibility-depth record, based on lithology and biostratigraphy (Cochran, Stow et al., 1989), but no convincing correlations were found.

The lack of correlation may be a result of several factors. Seismic records show that between Site 717 and its companion 719 most of the syn-deformation sediment layers either thin, pinch-out, or have been eroded (Cochran, Stow, et al., 1989). Even so, we were surprised that some of the larger turbidites, several meters thick, did not obviously correlate between holes. The magnetic signal is clearly detrital, not authigenic, so the differences must be because of sedimentary processes; the following are several possible explanations. Perhaps the differences are an indication that the turbidity currents were narrow or laterally constrained by channels in this part of the fan and so we are actually seeing signals from different turbidites. Another factor may be the topography of the fault block on which the two sites reside. The northern edge of the block may have protruded from the seafloor, possibly diverting turbidity currents and accentuating the differences between the two sites. Additionally, if there was erosion of these sediment layers, then there may have also been redeposition, rearranging the magnetic signal.

Our magnetic property studies also provide some insight into the unreliable geomagnetic field recording properties displayed by many Leg 116 samples (Hall and Sager, this volume). Many sediments that reliably preserve the geomagnetic field direction have tiny magnetic particles that fit within the interstices of the larger sediment grains. Consequently, they are mobile until sometime after burial when compaction and dewatering fix their positions, which are usually oriented parallel to the ambient magnetic field direction (Verosub, 1977). This type of sedimentary magnetization is termed a post-depositional remanent magnetization (PDRM). The Leg 116 black mud turbidite sediments, however, have large magnetic grains that are probably fixed as soon as the sedi- 
ment is deposited, giving rise to a depositional remanent magnetization (DRM). Such magnetizations are often found to be inaccurate magnetic field recorders, particularly for paleomagnetic inclination (Verosub, 1977; Barton et al., 1980). However, "inclination error" should not be a problem for the Leg 116 sediments as they were deposited near the Equator, where such effects are supposed to be minimal, so there may be other depositional factors operating as well. Indeed, the turbulence during deposition within the turbidites may have effectively jumbled the magnetic grains or aligned them in unpredictable ways. Moreover, the low coercivities and high concentrations of these grains probably gives them a propensity for acquiring a strong magnetization from a brief exposure to strong magnetic field, such as that believed to occur in the vicinity of the drill string used aboard the JOIDES Resolution.

\section{CONCLUSIONS}

The unusually magnetic black mud turbidites cored on ODP Leg 116 owe their magnetic properties mainly to detrital titanomagnetite grains mixed with a small amount of hematite. Magnetically, these layers are very distinct from the surrounding sediments whose magnetism appears to result solely from hematite. SIRM-susceptibility ratio and SEM observations suggest that the dominant titanomagnetite grains have a size generally in the 4 to $10-\mu \mathrm{m}$ range, with some as large as 20-25 $\mu \mathrm{m}$. Despite this relatively large grain size, the particles seem to behave as SD or PSD grains, perhaps because of their tabular shape or exsolution into a trellis pattern of small magnetite grains separated by ilmenite lamellae. However, their large size may not allow them to act as accurate geomagnetic field recorders when deposited in these turbidites. EDX analyses show that these grains contain significant but variable amounts of titanium, consistent with an iron-titanium ratio near 1 .

The titanomagnetite grains are characterized by low coercivities and MDF values. However, their susceptibility and NRM values are large and they acquire large ARMs and SIRMs, far greater than surrounding sediments. Additionally, they have distributed blocking temperatures, with a significant component remaining on thermal demagnetization to $300^{\circ} \mathrm{C}$ that virtually disappears by heating to $575^{\circ} \mathrm{C}$. The greatest slope of thermal demagnetization curves occurs in the $280^{\circ}-$ $330^{\circ} \mathrm{C}$ range, consistent with expected Curie temperatures for titanomagnetite grains with iron-titanium ratios varying about unity. Many of these properties match those of Deccan flood basalts, suggesting that this formation is the source of the magnetic particles found in these sediments.

Distinctive susceptibility peaks caused by the black mud turbidites appear to be primarily a result of variations in the concentration of titanomagnetite grains by a factor of about 10 , from $0.01 \%$ to $0.1 \%$. These concentration variations, and the shapes of the susceptibility peaks they create, evidently reflect variations in sedimentation processes acting on the titanomagnetite grains. On the one hand, these particles are heavier than other sediment particles and hence they tend to settle to the bottom of a density stratified layer. However, they have tabular shapes and are only in the middle of the range of particle sizes in these sediments, so turbidite turbulence may allow other larger and more rounded grains to be deposited first. The susceptibility signature of the turbidite is either symmetric or increasing downward depending on which process is dominant. Furthermore, multiple peaked susceptibility signals probably result from variations in turbidity current speed or concentrations of titanomagnetite grains within the current.

\section{ACKNOWLEDGMENTS}

We are indebted to Chad McCabe for the use of his laboratory and advice. We thank Lisa Donaghe, of the Texas A\&M University Electron Microscopy Center, for assistance with SEM and EDX analysis. We also thank H. P. Johnson and J. King for helpful reviews. This research was supported by a grant from JOI-USSAC.

\section{REFERENCES}

Backman, J., Duncan, R. A., et al., 1988. Proc. ODP, Init. Repts., 115: College Station, TX (Ocean Drilling Program).

Banerjee, S. K., King, J. and Marvin, J., 1981. A rapid method for magnetic granulometry with applications to environmental studies. Geophys. Res. Lett., 8:333-336.

Barker, P. F., Kennett, J. P., et al., 1988. Proc. ODP, Init. Repts., 113: College Station, TX (Ocean Drilling Program).

Barton, C. E., and McElhinny, M. W., and Edwards, D. J., 1980. Laboratory studies of depositional DRM. Geophys. J. R. Astron. Soc., 61:355-377.

Bloemendal, J., Oldfield, F., and Thompson, R., 1979. Magnetic measurements used to assess sediment influx at Llyn Goddionduan. Nature, 280:50-53.

Butler, R. F., and Banerjee, S. K., 1975. Theoretical single domain grain size range in magnetite and titanomagnetite. J. Geophys. Res., 80:4049-4058.

Canfield, D. E., and Berner, R. A., 1987. Dissolution and pyritization of magnetite in anoxic marine sediments. Geochim. Cosmochim. Acta, 51:645-659.

Ciesielski, P. F., Kristoffersen, Y., et al., 1988. Proc. ODP, Init. Repts., 114: College Station, TX (Ocean Drilling Program).

Cochran, J. R., Stow, D.A.V., et al., 1989. Proc. ODP, Init. Repts., 116: College Station, TX (Ocean Drilling Program).

Collinson, D. W., 1983. Methods in Rock Magnetism and Palaeomagnetism: New York (Chapman Hall).

Courtillot, V., Besse, J., Vandamme, V., Montigny, R., Jaeger, J., and Capetta, H., 1986. Deccan flood basalts at the Cretaceous/ Tertiary boundary? Earth Planet. Sci. Lett., 80:361-374.

Currie, R. G., and Bornhold, B. D., 1983. The magnetic susceptibility of continental shelf sediments, west coast Vancouver Island, Canada. Mar. Geol., 51:115-127.

Day, R., Fuller, M., and Schmidt, V. A., 1977. Hysteresis properties of titanomagnetites: grain-size and compositional dependence. Phys. Earth Planet. Interiors, 13:260-267.

Dunlop, D. J., 1973. Superparamagnetic and single-domain threshold sizes in magnetite. J. Geophys. Res., 78:1780-1793.

1986. Hysteresis properties of magnetite and their dependence on particle size: a test of pseudo-single-domain remanence models. J. Geophys. Res., 91:9569-9584.

Henshaw, P. C., Jr., and Merrill, R. T., 1980. Magnetic and chemical changes in marine sediments. Rev. Geophys. Space Phys., 18:483504.

Johnson, H. P., Lowrie, W., and Kent, D. V., 1975. Stability of anhysteretic remanent magnetization in fine and coarse magnetite and maghemite particles. Geophys. J. R. Astron. Soc., 41:1-10.

Karlin, R., and Levi, S., 1983. Geochemical and sedimentological control of the magnetic properties of hemipelagic sediments. $J$. Geophys. Res., 90:10373-10392.

Keating, B. H., 1984. Magnetometer measurements on the drilling floor of the Glomar Challenger: possible causes of rock remagnetization. In Hay, W. W., Sibuet, J.-C., et al., Init. Repts. DSDP, 75: Washington, D. C. (U.S. Government Printing Office), 12191226.

King, J., Banerjee, S. K., Marvin, J., and Ozdemir, O., 1982. A comparison of different magnetic methods for determining the relative grain size of magnetite in natural materials: some results from lake sediments. Earth Planet. Sci. Lett., 59:404-419.

Mascle, A., Moore, J. C., et al., 1988. Proc. ODP, Init. Repts. (Pt. A), 110: College Station, TX (Ocean Drilling Program).

McDougall, I., and McElhinny, M. W., 1970. The Rajmahal Traps of India-K-Ar ages and paleomagnetism. Earth Planet. Sci. Lett., 9:371-378. 
McElhinny, M. W., 1973. Palaeomagnetism and Plate Tectonics: London (Cambridge University Press).

Merrill, D. R., 1990. Magnetic susceptibility measurements of ODP Leg 112 cores (Peru Margin). In Suess, E. , Von Huene, R., et al., Proc. ODP, Sci. Results, 112: College Station, TX (Ocean Drilling Program), in press.

Mooney, H. M., and Bleifuss, R., 1953. Magnetic susceptibility measurements in Minnesota, part II: analysis of field results. Geophysics, 18:383-393.

Moskowitz, B. M., and Banerjee, S. K., 1979. Grain size limits for pseudo-single domain behavior in magnetite: implications for palecmagnetism. IEEE Trans. Mag., 5:1241-1246.

Mullins, C. E., 1977. Magnetic susceptibility of the soil and its significance in soil science-a review. J. Soil Sci., 28:223-246.

Parry, L. G., 1965. Magnetic properties of dispersed magnetite powders. Phil. Mag., 11:303-312.

Robinson, S. G., 1986. The late Pleistocene palaeoclimatic record of North Atlantic deep-sea sediments revealed by mineralmagnetic measurements. Phys. Earth Planet. Interiors, 42:2247.

Rochette, P., 1987. Metamorphic control of the magnetic mineralogy of black shales in the Swiss Alps: toward the use of "magnetic isogrades". Earth Planet. Sci. Lett., 84:446-456.

Ruddiman, W., Sarnthein, M., et al., 1988. Proc. ODP, Init. Repts., 108: College Station, TX (Ocean Drilling Program).

Sager, W. W., and Hutton, H. H., 1986. Magnetic field measurements aboard the JOIDES Resolution and implications for shipboard paleomagnetic studies. In Austin, J. A., Jr., Schlager, W., et al., Proc. ODP, Init. Repts., 101: College Station, TX (Ocean Drilling Program), 33-37.
Srivastiva, S. P., Arthur, M. A., et al., 1987. Proc. ODP, Init. Repts., 105: College Station, TX (Ocean Drilling Program).

Strangway, D. W., 1970. History of the Earth's Magnetic Field: New York (McGraw-Hill).

Talukdar, S. C., and Murty, M.V.N., 1971. The Sylhet Traps, their tectonic history, and their bearing on problems of Indian flood basalt provinces, Bull. Volcanol., 35:602-618.

Thompson, R., Battarbee, R. W.., O'Sullivan, P. E., and Oldfield, F., 1975. Magnetic susceptibility of lake sediments. Limnol. Oceanogr., 20:687-698.

Thompson, R., Bloemendal, J., Dearing, J. A., Oldfield, F., Rummery, T. A., Stober, J. C., and Turner, G. M., 1980. Environmental applications of magnetic measurements. Science, 207:481-486.

Thompson, R., and Morton, D. J., 1979. Magnetic susceptibility and particle-size distribution in recent sediments of Loch Lomond drainage basin, Scotland. J. Sediment. Petrol., 49:801-812.

Thompson, R., and Oldfield, F., 1986. Environmental Magnetism: London (Allen and Unwin).

Verma, R. K., and Pullaiah, G., 1971. Paleomagnetic study of a vertical sequence of Deccan Traps from Jabalpur. Bull. Volcanol., 35:750-765.

Verosub, K. L., 1977. Depositional and postdepositional processes in the magnetization of sediments. Rev. Geophys. Space Phys., 15:129-143.

Wensink, H., 1973. Newer paleomagnetic results from the Deccan Traps, India. Tectonophysics, 17:41-59.

Date of initial receipt: 19 June 1989

Date of acceptance: 3 January 1990

Ms 116B-141 